\title{
Pharmacokinetic and nephroprotective benefits of using Schisandra chinensis extracts in a cyclosporine A-based immune-suppressive regime
}

This article was published in the following Dove Press journal:

Drug Design, Development and Therapy

28 August 2015

Number of times this article has been viewed

\author{
Qiao Lai' \\ Jiabao Wei' \\ Mohammed \\ Mahmoodurrahman ${ }^{2}$ \\ Chenxue Zhang' \\ Shijian Quan' \\ Tongming $\mathrm{Li}^{\prime}$ \\ Yang $\mathrm{Yu}^{\prime}$ \\ 'Department of Formulas of \\ Traditional Chinese Medicine, \\ School of Chinese Materia Medica, \\ Guangzhou University of Chinese \\ Medicine, Guangzhou, Guangdong, \\ People's Republic of China; ${ }^{2}$ College \\ of Medicine, Alfaisal University, \\ Riyadh, Saudi Arabia
}

\begin{abstract}
Cyclosporine A (CsA) is a powerful immunosuppressive drug. However, nephrotoxicity resulting from its long-term usage has hampered its prolonged therapeutic usage. Schisandra chinensis extracts (SCE) have previously been used in traditional Chinese medicine and more recently coadministered with Western medicine for the treatment of CsA-induced side effects in the People's Republic of China. This study aimed to investigate the possible effects of SCE on the pharmacokinetics of CsA in rats and elucidate the potential mechanisms by which it hinders the development of CsA-induced nephrotoxicity. A liquid chromatography/ tandem mass spectrometry method was developed and validated for determining the effect of SCE on the pharmacokinetics of CsA. Male Sprague Dawley rats, which were administered with CsA (25 mg/kg/d) alone or in combination with SCE (54 mg/kg/d and $108 \mathrm{mg} / \mathrm{kg} / \mathrm{d})$ for 28 days, were used to evaluate the nephroprotective effects of SCE. Our study showed that SCE increased the mean blood concentration of CsA. Furthermore, we found that the concomitant administration of SCE alongside CsA prevented the disruption of catalase activity and reduction in creatinine, urea, renal malondialdehyde, and glutathione peroxidase levels that would have otherwise occurred in the absence of SCE administration. SCE treatment markedly suppressed the expression of 4-hydroxynonenal, Bcl-2-associated X protein, cleaved caspase 3, and autophagy-related protein LC3 A/B. On the other hand, the expression of heme oxygenase-1, nuclear factor erythroid 2-related factor 2 (Nrf2), and P-glycoprotein was enhanced by the very same addition of SCE. SCE was also able to increase the systemic exposure of CsA in rats. The renoprotective effects of SCE were thought to be mediated by its antiapoptotic and antioxidant abilities, which caused the attenuation of CsA-induced autophagic cell death. All in all, these findings suggest the prospective use of SCE as an effective adjunct in a CsA-based immunosuppressive regimen.
\end{abstract}

Keywords: Schisandra chinensis extracts, cyclosporine A, pharmacokinetics, nephroprotective, oxidative stress, apoptosis, autophagy

\section{Introduction}

Cyclosporine A (CsA), a potent immunosuppressant, is the most widely used drug in organ transplantation and in the management of several autoimmune disorders. ${ }^{1}$ Despite being so very potent, its use for therapeutic purposes remains challenging due to the occurrence of disastrous side effects, namely, acute and chronic nephrotoxicity, severe hypertension, and neurotoxicity. ${ }^{2,3}$ Experimental studies have shown that CsA-induced nephrotoxicity is characterized by progressive irreversible renal structural damage, arteriopathy of the afferent arterioles, tubulointerstitial inflammation, striped fibrosis, and decreased glomerular filtration rate. ${ }^{4}$ However, the mechanism underlying CsA-induced renal damage is not fully understood. Recent studies have
School of Chinese Materia Medica, Guangzhou University of Chinese Medicine, Guangzhou, Guangdong 510006, People's Republic of China Tel +862039358094

Fax +86 2039358090

Email yuyang@gzucm.edu.cn 
demonstrated that CsA-induced oxidative stress, apoptotic cell death, and excessive autophagosome formation play a crucial role in causing structural and functional kidney impairment. ${ }^{5-7}$ The CsA-induced autophagy has been shown to be triggered by endoplasmic reticulum stress. ${ }^{8}$ Alternatively, other reports have revealed that CsA can induce apoptosis in human proximal cells in vitro via reactive oxygen species (ROS)-mediated cell damage. ${ }^{9,10}$ Then, CsA has been shown to be able to induce renal dysfunction and cause altered renal morphology through mechanisms in addition to the side effects mentioned previously, including inflammation, apoptosis, autophagy, and generation of oxidative radicals. $^{8,11-13}$

Schisandra chinensis (Turcz, Bail), a member of Magnoliaceae family, has been one of the most widely used traditional herbal medicines in traditional Chinese medicine for thousands of years in People's Republic of China. ${ }^{14,15}$ The use of $S$. chinensis, as a superior herbal medicine, was first recorded in the ancient pharmaceutical book The Divine Husbandman's Herbal Foundation Canon (Shen Nong Ben Tsao Ching). ${ }^{16}$ Schisandra lignans, which have a dibenzocyclooctadiene skeleton, are the major constituents of S. chinensis and from them $>40$ ingredients have been isolated until now, including deoxyschizandrin, schizandrin, schizantherin A, and schizanhenol. ${ }^{17}$ Additionally, the $S$. chinensis extracts (SCE) have been revealed to possess multipharmaceutical bioactivities, including antioxidant, anti-inflammatory, antimicrobial, cardioprotective, hepatoprotective, antiseptic, and antitumor properties, which are extremely useful for the treatment of hepatitis, renal insufficiency, menstrual disorders, and neuroasthenia. ${ }^{18}$ Schizandrin and schinzandrin B, both components of the SCE, have been shown to exhibit renoprotective effects by preventing cell death. It has been found that SCE causes enhancement of tubular regeneration in $\mathrm{HK}-2$ cells models affected by cisplatin-induced nephrotoxicity and thereby prevents potential damage from occurring. ${ }^{19}$ It has further been reported that SCE might be beneficial for diabetic nephropathy, where SCE by maintaining podocyte integrity through suppression of epithelial to mesenchymal transition leads to the attenuation of albuminuria and glomerulosclerosis. ${ }^{20}$ Recently in a study, schizandrin B was shown to suppress hypoxia/reoxygenation-induced apoptosis of $\mathrm{H} 9 \mathrm{c} 2$ cells in vitro. ${ }^{21}$ In another study, SCE was found to be able to inhibit fiber formation and cell migration in vascular smooth muscle cell by reducing transforming growth factor beta 1-mediated phosphorylation of myosin light chain. This effect was shown to be independent of RhoA/Rho-associated kinase pathway. ${ }^{22}$ Though many studies have been conducted on SCE functions, the potential renoprotective and molecular mechanism underlying the benefits of SCE on CsA-induced nephrotoxicity remains to be explored.

This study was designed to evaluate the effects of SCE on the pharmacokinetics of CsA and elucidate the protective effects of SCE on CsA-induced renal injury using salt-depleted rat model of CsA nephropathy. It has been hypothesized that SCE can elevate the blood concentration of CsA, and at the same time, it can also ameliorate renal dysfunction and structural damage through its antioxidant, antiapoptotic, and autophagic properties. In this study, CsA levels in the blood sample were determined using liquid chromatography/ tandem mass spectrometry methods. To test for oxidative renal damage, we searched for the relevant biochemical and histopathological changes in renal tissue. Finally, Western blot and immunohistochemical techniques were put to use in order to demonstrate the expression of heme oxygenase-1 (HO-1), nuclear factor erythroid 2-related factor 2 (Nrf2), P-glycoprotein (P-gp), cleaved caspase 3, Bcl-2-associated $\mathrm{X}$ protein (Bax), and LC3A/B protein in the renal tissue.

\section{Materials and methods Chemicals and reagents}

S. chinensis was purchased from Daxiang Pharmaceuticals Inc. (Guangzhou, Guangdong, People's Republic of China). Cyclosporine A (CsA) soft capsules, provided by Novartis International AG (Basel, Switzerland), were diluted in olive oil (Sigma-Aldrich Co., St Louis, MO, USA). CsA, schizandrin, schizandrin A, and schizandrin B, all of which had a purity of $98 \%$ as determined by ultraviolet (UV) detection using high-performance liquid chromatography (HPLC), were synthesized and provided by National Institutes for Food and Drug Control (Beijing, People's Republic of China). Ascomycin (FK520, as the internal standard), which had a purity of $95 \%$ as determined by UV detection using HPLC, was synthesized and provided by Melonepharma Bio Inc. (Dalian, People's Republic of China). Methanol and acetonitrile of HPLC grade were purchased from Merck \& Co., Inc. (Whitehouse Station, NJ, USA). Primary antibodies against HO-1, 4-hydroxynonenal (4-HNE), Nrf2, P-gp, and Bax were purchased from Abcam Inc. (Cambridge, MA, USA). Primary antibodies against cleaved caspase 3 and LC3A/B were bought from Cell Signaling Technology (Boston, MA, USA). All other reagents were of analytical grade or HPLC grade, where appropriate. Ultrapure water was obtained from a Mill-Q Plus system (Billerica, MA, USA).

\section{Animals}

Male Sprague Dawley rats (weighing 220-250 g) were obtained from the Experimental Animals Center of Guangzhou 
University of Chinese Medicine. The animals were housed in a room with temperature- and light-controlled environment. The animals had free access to low salt diet $(0.04 \%$ sodium, provided by Medical Laboratory Animal Center, Guangdong, People's Republic of China) and tap water. The Institutional Animal Care and Use Committee of Guangzhou University of Chinese Medicine approved this experimental protocol, and all procedures performed in this study followed the regulations of experimental animal administration issued by the Ministry of Science and Technology of the People's Republic of China.

\section{SCE preparation}

SCE was made as described in our previously published paper. ${ }^{23}$ Briefly, $95 \%$ ethanol was added to the $S$. chinensis fruit. Circumfluent extraction was then performed three times lasting 3 hours each. This was followed by macroporous resin (AB-8) purification using 75\% ethanol, the solvent used for eluting. To examine the total content of lignanoids within SCE, a quota of SCE $(60 \mu \mathrm{L})$ was examined at $570 \mathrm{~nm}$ on a UV-6100S UV-visible scanning spectrophotometer (Shanghai Precision Instrument Co. Ltd., Shanghai, People's Republic of China). The total lignans content in the prepared $\mathrm{SCE}$ was calculated to be $37.30 \mathrm{mg} / \mathrm{g}$. HPLC was performed to determine the components of SCE using an Agilent 1100 liquid chromatography system (Agilent Technologies, Santa Clara, CA). In this study, the retention times of standard control samples of schizandrin, schizandrin A, and schizandrin B were 7.640 minutes, 22.587 minutes, and 33.368 minutes, respectively (Figure 1A). Accordingly, the contents of schizandrin, schizandrin A, and schizandrin B in three major bioactive compounds in three batches of SCE were calculated as $5.26-5.41 \mathrm{mg} / \mathrm{g}, 1.68-1.77 \mathrm{mg} / \mathrm{g}$, and $0.721-0.797 \mathrm{mg} / \mathrm{g}$, respectively (Figure 1B).

\section{Pharmacokinetic study in rats}

All rats were deprived of food for 12 hours before blood sample obtainment. Subsequently, the rats were randomly divided into four groups, each group consisting of six rats ( $n=6): 1$ ) CsA-only group: rats were administered tap water simultaneously with CsA $(25 \mathrm{mg} / \mathrm{kg})$ in a span of 10 minutes. 2) SCE administered at a dose of $54 \mathrm{mg} / \mathrm{kg}$. 3) SCE administered at a dose of $108 \mathrm{mg} / \mathrm{kg}$. 4) SCE administered at a dose of $216 \mathrm{mg} / \mathrm{kg}$. In the latter three groups: SCE was administered by gavage to the animals at relevant doses, and 10 minutes post-SCE administration, all rats were given CsA at a dose of $25 \mathrm{mg} / \mathrm{kg}$. Both SCE and CsA were given in an administration volume of $10 \mathrm{~mL} / \mathrm{kg}$ body weight.

Blood sample $(400 \mu \mathrm{L})$ was collected using heparinized tubes through the jugular vein at 0 hour, 0.083 hour, 0.25 hour, 0.5 hour, 0.75 hour, 1.0 hour, 2.0 hours, 3.0 hours, 4.0 hours, 6.0 hours, 8.0 hours, 12.0 hours, 24.0 hours, 36.0 hours, and 48.0 hours. Whole blood sample $(100 \mu \mathrm{L})$ was pipetted into a microcentrifuge tube; $50 \mu \mathrm{L}$ of $0.1 \mathrm{M} \mathrm{ZnSO}_{4}$ solution and $800 \mu \mathrm{L}$ of methanol/acetonitrile $(50: 50, \mathrm{v} / \mathrm{v})$ were added to the whole blood sample. The mixture was vortexed for
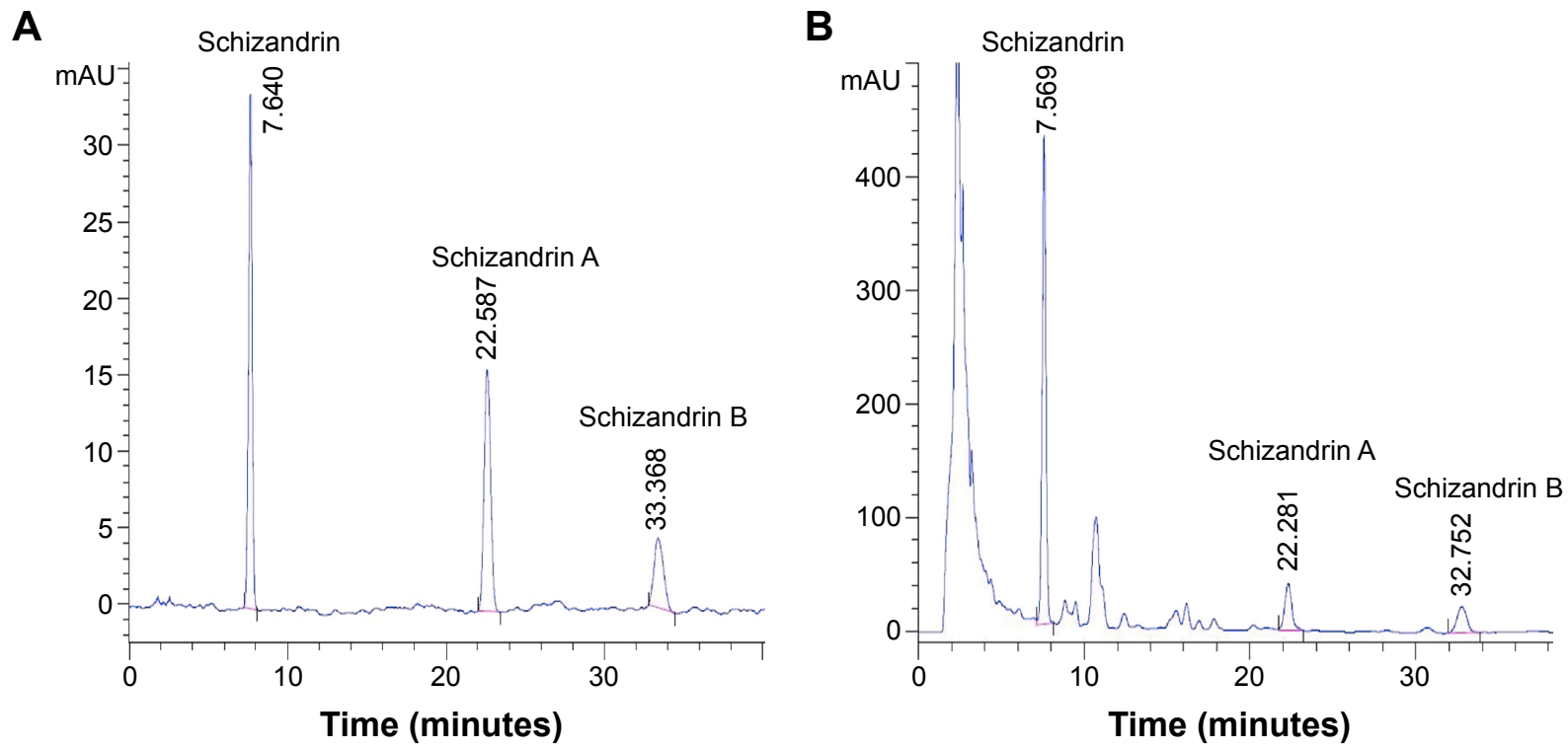

Figure I Evaluation of the components in Schisandra chinensis extracts (SCE) using high-performance liquid chromatography assay.

Notes: (A) The mixture of the three reference compounds. (B) The sample of SCE. Chromatographic separation was performed on a Kromasil CI 8 column (250 mm $\times 4.6 \mathrm{~mm}$ id, $5 \mu \mathrm{m}$ ) at $35^{\circ} \mathrm{C}$. The mobile phase consisted of eluents $A$ (water) and B (methanol). The elution program was optimized and conducted as follows: a linear gradient of $68-70 \%$ B (0-5 minutes), a linear gradient of 70-75\% B (5-15 minutes), an isocratic elution of 75\% B ( $15-38$ minutes), a linear gradient of 75-68\% B (38-39 minutes), an isocratic elution of $68 \% \mathrm{~B}$ ( $39-45$ minutes). The peaks were recorded using PDA absorbance at $254 \mathrm{~nm}$ and the solvent flow rate was kept at $1.0 \mathrm{~mL} / \mathrm{min}$. 
2 minutes and then centrifuged at 16,000 rpm for 15 minutes. Thereon, the upper phase was transferred to a clean centrifuge tube and evaporated to dryness. The residues were dissolved in $200 \mu \mathrm{L}$ of methanol, vortexed for 3 minutes, and centrifuged at $16,000 \mathrm{rpm}$ for 10 minutes.

\section{Quantification of CsA by liquid chromatography/tandem mass spectrometry}

Chromatographic analysis was performed using the Agilent 1260 series HPLC system, and the separation was performed using a $\mathrm{C}_{18}$ column $(2.1 \times 50 \mathrm{~mm}, 3.5 \mu \mathrm{m}$ particle size, internal diameter; Waters, USA) at $60^{\circ} \mathrm{C}$. The mobile phase consisted of methanol-water $(80: 20, \mathrm{v} / \mathrm{v}$, containing $10 \mathrm{mM}$ ammonium acetate), and it was pumped at a flow rate of $0.2 \mathrm{~mL} / \mathrm{min}$. The total running time was 5 minutes for each sample. The chromatographic peak was confirmed by liquid chromatography/mass spectrometry experiment using the Agilent 6460 triple-quadrupole mass spectrometer under a positive electrospray ionization mode, with the spray voltage set at 3,500 V. Desolvation gas (nitrogen) was heated to $300^{\circ} \mathrm{C}$ and delivered at a flow rate of $5 \mathrm{~L} / \mathrm{min}$. The nitrogen nebulizing gas was set at 45 psi. The tandem mass spectrometry detection was conducted by monitoring the fragmentation of $m / z \quad 1,219.9 \rightarrow 1,203.7$ for CsA (Figure 2A) and $m / z \quad 809.5 \rightarrow 792.5$ for FK520 (Figure 2B). The method was validated for selectivity, calibration curve, recovery, precision, the lower limit of quantification, and stability according to the US Food and Drug Administration guideline for validation of bioanalytical methods.

\section{SCE protects against CsA-induced nephrotoxicity study in rats}

Forty-two rats were randomized into six subgroups of seven rats each and treated daily for 28 days as follows: 1) Control
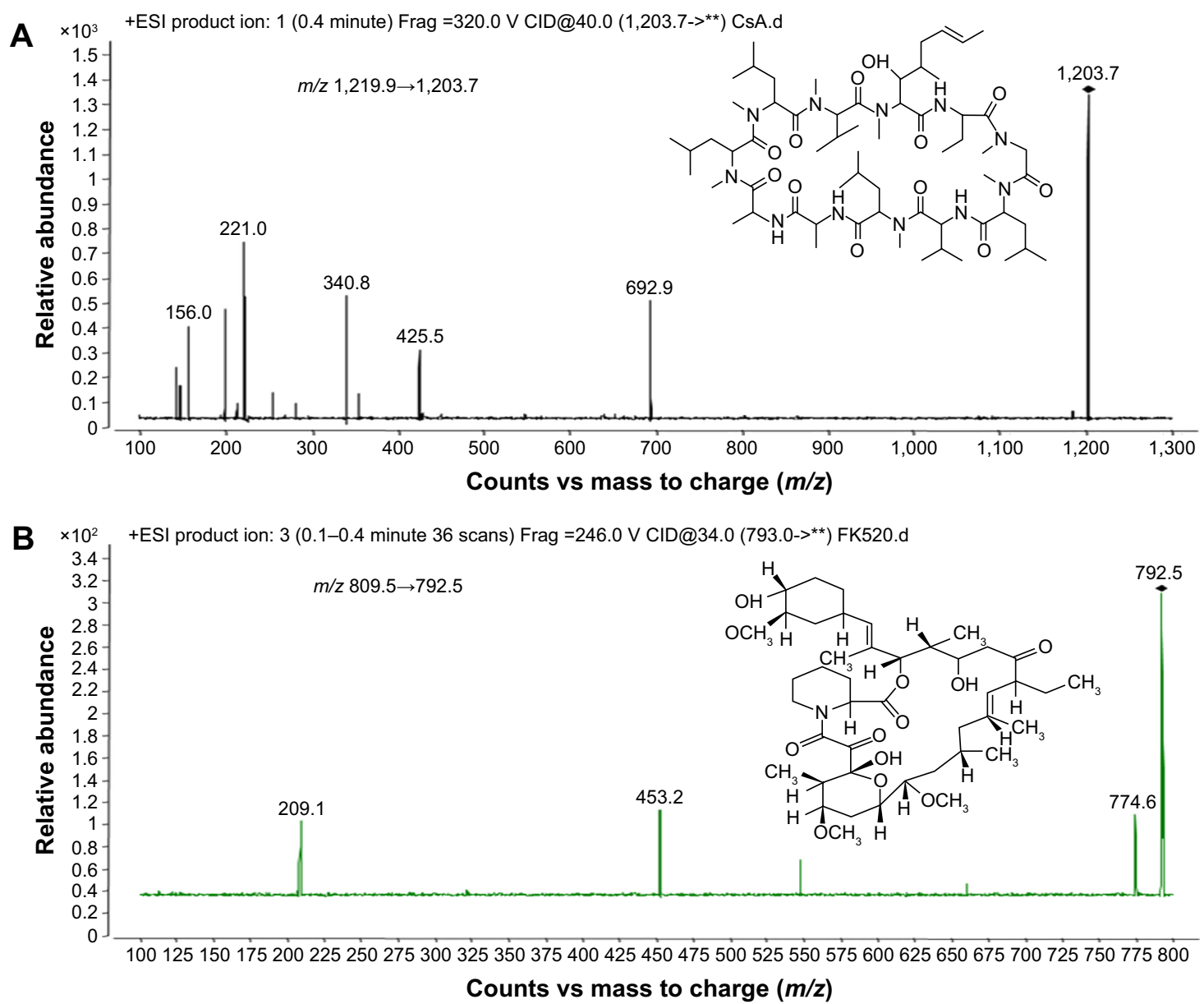

Figure 2 Full-scan product ion of precursor of (A) CsA and (B) FK520.

Notes: The chromatographic peak was confirmed by LC-MS experiment using the Agilent 6460 triple-quadrupole mass spectrometer under a positive electrospray ionization (ESI) mode, with the spray voltage set at $3500 \mathrm{~V}$. Desolvation gas (nitrogen) was heated to $300^{\circ} \mathrm{C}$ and delivered at a flow rate of $5 \mathrm{~L} / \mathrm{min}$. The nitrogen nebulizing gas was set at 45 psi. Abbreviation: CsA, cyclosporine A. 
group: gavaged with tap water $(10 \mathrm{~mL} / \mathrm{kg})$ and fed normal salt diet for 28 days. 2) Vehicle control group: gavaged with olive oil $(10 \mathrm{~mL} / \mathrm{kg})$ and fed low salt diet for 28 days. 3) CsA group: gavaged with $25 \mathrm{mg} / \mathrm{kg}$ CsA and fed low salt diet for 28 days in order to establish a nephrotoxic effect. 4) SCE group: gavaged with $108 \mathrm{mg} / \mathrm{kg} \mathrm{SCE}$ and fed low salt diet for 28 days. 5) $54 \mathrm{mg} / \mathrm{kg} \mathrm{SCE}+$ CsA group: gavaged with $54 \mathrm{mg} / \mathrm{kgSCE}+25 \mathrm{mg} / \mathrm{kg}$ CsA and fed low salt diet for 28 days. 6) $108 \mathrm{mg} / \mathrm{kg} \mathrm{SCE}+25 \mathrm{mg} / \mathrm{kg}$ CsA group: gavaged with $108 \mathrm{mg} / \mathrm{kgSCE}+25 \mathrm{mg} / \mathrm{kg}$ CsA and fed low salt diet for 28 days.

After the aforementioned 28 days, the rats, who fasted overnight, were anesthetized with pentobarbital sodium (40 mg/kg, intraperitoneal). Blood samples were collected from aorta abdominalis, and these samples were then separated by the process of centrifugation at $4,000 \mathrm{rpm}$ within a span of 10 minutes. The serum was aspirated and stored at $-80^{\circ} \mathrm{C}$ until it was needed for biochemical analyses. Following blood collection, rats were sacrificed by overdosing them with pentobarbital sodium. Thereafter, their abdomens were opened and a longitudinal section of the right kidney was taken and fixed in $10 \%$ formaldehyde at $4^{\circ} \mathrm{C}$ for 48 hours. These longitudinal sections from each animal were then embedded in paraffin blocks for histopathological and immunohistochemical analyses. The renal cortex of the left kidney was frozen in liquid nitrogen and stored at $-80^{\circ} \mathrm{C}$ for Western blot and various biochemical analyses.

\section{Biochemical analysis}

Using commercially available kits, levels of serum creatinine $(\mathrm{Cr})$ and serum urea, malondialdehyde (MDA) levels (JianCheng Bioengineering Institute, Nanjing, People's Republic of China), as well as catalase (CAT) activity and glutathione peroxidase (GSH-Px) activity (Beyotime, Jiangsu, People's Republic of China) were quantified according to the manufacturers' guidelines. The protein concentration was determined using the bicinchoninic acid Protein Assay Kit (Beyotime), which is based on an absorbance shift in bicinchoninic acid.

\section{Histopathological analysis}

The longitudinal sections of the right kidney were fixed using $10 \%$ neutral phosphate-buffered formalin solution. For light microscopy, they were first dehydrated using a series of ethanol solutions $(70 \%, 80 \%, 95 \%$, and $100 \%)$, then processed in an autotechnicon, and finally embedded in paraffin. Sections 4-5 $\mu \mathrm{m}$ thick were cut by a rotary microtome (Leica Microsystems, Wetzlar, Germany) and stained by hematoxylin-eosin
(H\&E) and Masson's trichrome to evaluate for tubular necrosis and interstitial fibrosis. The stained specimens were examined by a blinded pathologist using an Olympus CX31 (Olympus Corporation, Tokyo, Japan) light microscope.

Tubular necrosis (dilation and vacuolation), inflammatory cell infiltrate, brush border loss, and the presence of cells or cellular debris in tubular lumens were perused for and histopathological scoring of H\&E-stained sections performed. Twelve random sections $(\times 200)$ from each kidney were analyzed, and histopathological damage score categorized to be in the range $0-3.1$ ) score 0 : damage affecting no $<5 \%$ of the field; 2) score 1: damage affecting $5 \%-25 \%$ of the field; 3) score 2 : damage affecting $25 \%-75 \%$ of the field; and 4) score 3: damage exceeding $75 \%$ of the field. All 12 scores were added to give the total necrosis score for each kidney.

Collagen deposits were determined by the development of deep green color after Masson's trichrome staining of tissue sections. Briefly, $4-5 \mu \mathrm{m}$ paraffin sections were deparaffinized and stained with Weigert's hematoxylin for 10 minutes. Thereafter, these sections were further stained first with a solution containing chromotropic acid, phosphotungstic acid, and glacial acetic acid for 10 minutes, followed by $0.5 \%$ light green solution for another 5 minutes. Collagen deposition in the cortex was quantified in 20 fields at $\times 200$ magnification using the Image-Pro Plus software (Media Cybernetics, Rockville, MD, USA).

\section{Immunohistochemical analysis}

Paraffin-embedded kidney sections of $5 \mu \mathrm{m}$ thickness were placed on adhesion microscope slides (CITOGLAS, Citotest Labware Manufacturing Co., Ltd, Jiangsu, People's Republic of China), deparaffinized in xylene, and then rehydrated in graded decreasing ethanol concentrations $(100 \%, 95 \%, 80 \%$, $70 \%$, and $50 \%$ ). Slides were rinsed gently with phosphatebuffered saline (PBS, pH 7.2) solution for 5 minutes and drained. The antigenic determinants in the kidney cells were unblocked by incubating the sections at $98^{\circ} \mathrm{C}$ for 20 minutes in $0.01 \mathrm{M}$ citrate buffer ( $\mathrm{pH}$ 6.0) to ensure heat-induced epitope retrieval. These sections were then rinsed with PBS (pH 7.2) for further 3 minutes. Additionally, endogenous peroxidases were blocked by adding $3 \%$ hydrogen peroxide, keeping for 10 minutes at room temperature, and then by washing with PBS (pH 7.2). The sections were then immunoassayed with primary antibodies (4-HNE, 1:200; cleaved caspase 3, 1:300; Bax, 1:250; and LC3A/B, 1:1,000, diluted with 5\% BSA in PBS ready to use) overnight in the humidity chamber at $4{ }^{\circ} \mathrm{C}$. Negative controls were processed without applying the primary antibodies. After washing three times, 
the sections were incubated for further 20 minutes with Polink-1 One-step polymer detection system kit (ZSGB-Bio Co. Ltd., Beijing, People's Republic of China). The chromogen 3,3'-diaminobenzidine system kit (ZSGB-Bio Co. Ltd.) was prepared and applied as instructed by the manufacturer for color reaction. The slides were then counterstained with hematoxylin and dehydrated in ascending concentrations of ethanol and then xylene, mounted. Every section was examined in a blinded manner using light microscopy (Olympus CX31; Olympus Corporation). For the quantification of the integral optical density of positively stained cells, the cells were counted in 20 consecutive high power fields at $\times 200$ magnification using the Image-Pro Plus software (Media Cybernetics).

\section{Western blot}

Renal tissues were homogenized in the radioimmunoprecipitation assay buffer, which contained the protease inhibitor cocktail and centrifuged at $11,000 \mathrm{rpm}$ for 10 minutes at $4{ }^{\circ} \mathrm{C}$. Protein concentration in the supernatants was measured using the bicinchoninic acid assay kit (Beyotime). An aliquot of the supernatant (30 $\mu \mathrm{g}$ protein) was then suspended in $4 \times$ Laemmli loading buffer that contained dithiothreitol. It was then boiled for 5 minutes at $100^{\circ} \mathrm{C}$, electrophoresed on $8 \%$ sodium dodecyl sulfate polyacrylamide gel electrophoresis gels at $150 \mathrm{~V}$ for 80 minutes, and subsequently transferred onto polyvinylidene difluoride membranes using a Trans-Blot semidry transfer cell (Bio-Rad Laboratories Inc., Hercules, CA, USA). After the transfer, the polyvinylidene fluoride membrane was blocked using 5\% skim milk at room temperature for 2 hours followed by incubation with the specific primary antibodies (4-HNE, Nrf2, HO-1, P-gp, Bax, cleaved caspase 3 , and LC3A/B were diluted at 1:1,000, respectively) at $4^{\circ} \mathrm{C}$ overnight. The samples were treated with antirabbit horseradish peroxidase-conjugated secondary antibodies at room temperature for 2 hours and visualized using the enhanced chemiluminescence detection system (Amersham Pharmacia Biotech, Piscataway, NJ, USA). Finally, the images were analyzed and quantified using Image J software (National Institutes of Health, Bethesda, MD, USA).

\section{Pharmacokinetic calculation and statistical analysis}

Pharmacokinetic parameters were calculated using a noncompartment model in a noncompartmental analysis performed by a pharmacokinetic program (Data Access Service, Version 2.1; Medical College of Wannan, Anhui, People's Republic of China). The grouped data were statistically analyzed by one-way analysis of variance (ANOVA) followed by the Newman-Keuls post hoc test using software Prism 5.0 (GraphPad Software, Inc., La Jolla, CA, USA). $P<0.05$ was considered to indicate statistically significant results. Data are presented as the mean \pm standard deviation from at least six independent experiments.

\section{Results \\ Methodological validation of CsA}

Representative chromatograms of the blank whole blood sample, blank whole blood sample spiked with CsA and FK520, and whole blood sample from a rat after a single oral administration of CsA (25 mg/kg) are shown in Figure 3. No interfering peaks were found at or near the retention time of CsA and FK520. In addition, the calibration curve of CsA in the whole blood of rats was established and exhibited a good linear response within the range of concentrations from $20 \mathrm{ng} / \mathrm{mL}$ to $5,000 \mathrm{ng} / \mathrm{mL}$ (the $R^{2}$ of calibration curves was 0.995$)$. Lower limit of quantification of the analytical method was $20 \mathrm{ng} / \mathrm{mL}$ for CsA. The extraction recovery and matrix effect of CsA are shown in Table 1. These results indicated that the extraction efficiency was excellent, and there was no matrix effect from the endogenous blood components of CsA. Table 2 summarizes the intraday and interday precision and accuracy of CsA measurements at three concentration levels. Stability samples, which were (at three levels) subject to short-term storage, posttreatment storage, three freeze-thaw cycles, and long-term storage, were examined for their stabilities, and the results are summarized in Table 3. These results were within the acceptance criteria and indicated that the method was accurate, reliable, and reproducible.

\section{Effect of different doses of SCE on the pharmacokinetics of CsA}

The mean whole blood concentration versus time curve is presented in Figure 4, and major pharmacokinetic parameters calculated by noncompartmental model are listed in Table 4. After the oral administration of different doses of SCE to rats, the whole blood concentrations of CsA were found to be increased. The apparent elimination half-life $\left(t_{1 / 2}\right)$ of CsA was significantly longer when it was administered with $216 \mathrm{mg} / \mathrm{kg}$ SCE than when it was administered solely. The time to reach the maximum $\left(T_{\max }\right)$ was delayed from $6.33 \pm 1.50$ hours to $6.8 \pm 1.10$ hours, $8.67 \pm 1.63$ hours, and 13.5 \pm 7.55 hours when CsA was administered with $54 \mathrm{mg} / \mathrm{kg}, 108 \mathrm{mg} / \mathrm{kg}$, and $216 \mathrm{mg} / \mathrm{kg}$ of SCE, respectively. The increase in $\mathrm{AUC}_{0-\mathrm{t}}$ and $\mathrm{AUC}_{0-\infty}$ was approximately twofold when CsA was administered in combination with $216 \mathrm{mg} / \mathrm{kg}$ SCE. Meanwhile, the clearance was reduced by approximately twofold, and the 

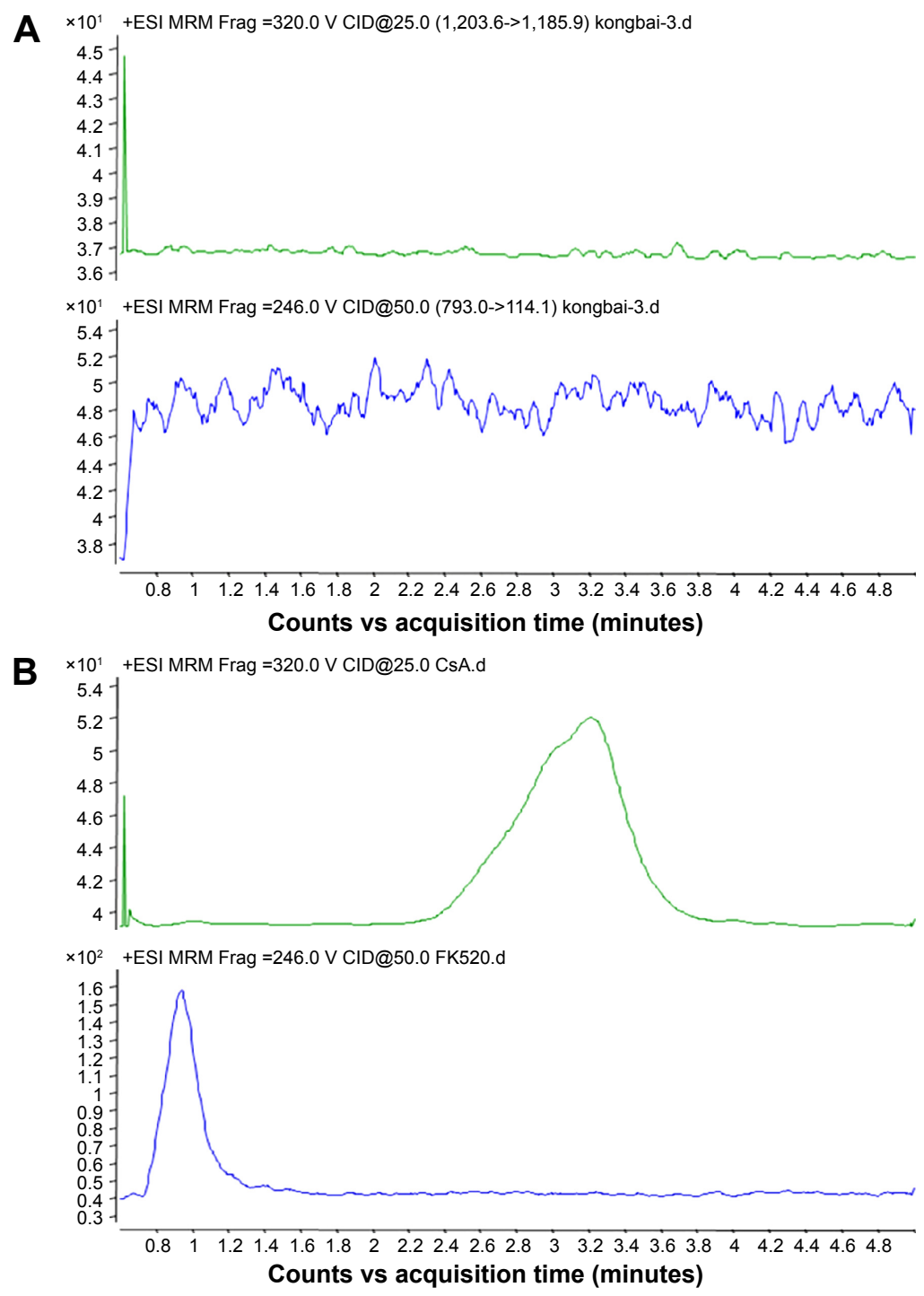

C $\times 10^{1}+$ ESI MRM Frag $=320.0 \mathrm{~V}$ CID@25.0 CsA.d
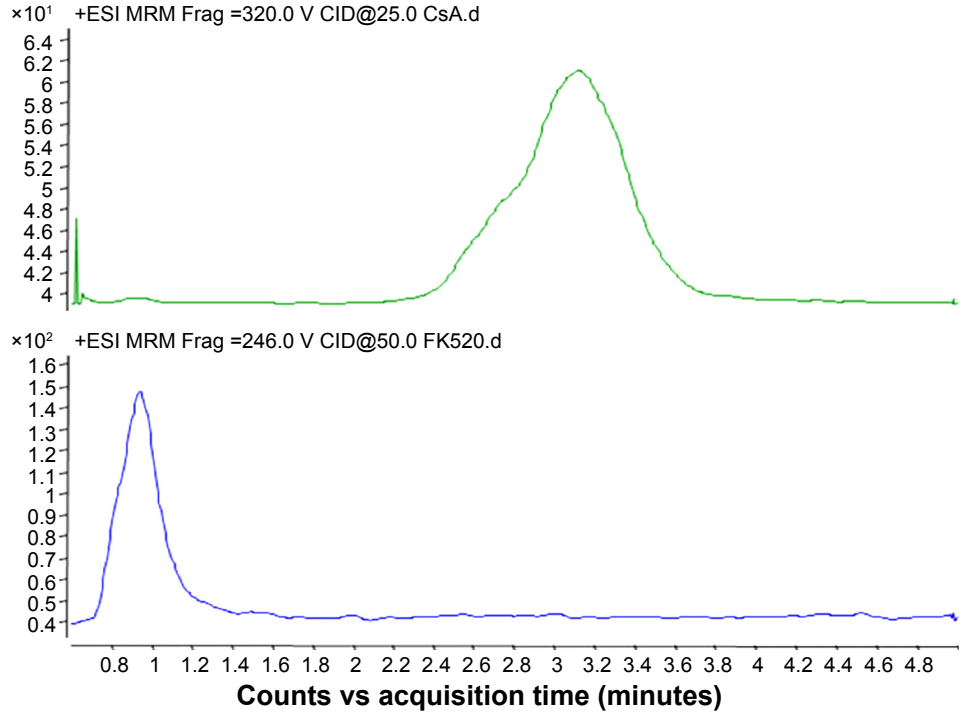

Figure 3 Representative multiple reaction monitoring (MRM) chromatograms of CsA and FK520 in rat whole blood. Notes: (A) A blank whole blood sample. (B) A blank whole blood sample spiked with CsA and FK520 at $50 \mathrm{ng} / \mathrm{mL}$. (C) A whole blood sample from a rat after a single oral administration of CsA $(25 \mathrm{mg} / \mathrm{kg})$.

Abbreviation: CsA, cyclosporine A. 
Table I The extraction recovery and matrix effect of CsA in rat whole blood sample at $50 \mathrm{ng} / \mathrm{mL}, 200 \mathrm{ng} / \mathrm{mL}, \mathrm{and} \mathrm{2,000} \mathrm{ng/mL}$ concentration levels $(n=6)$

\begin{tabular}{llll}
\hline $\begin{array}{l}\text { CsA concentration } \\
(\mathbf{n g} / \mathbf{m L})\end{array}$ & $\begin{array}{l}\text { Extraction recovery } \\
(\text { mean } \pm \text { SD, \%) }\end{array}$ & $\begin{array}{l}\text { RSD } \\
(\%)\end{array}$ & $\begin{array}{l}\text { Matrix effect } \\
(\text { mean } \pm \text { SD, \%) }\end{array}$ \\
\hline 50 & $72.97 \pm 7.51$ & 10.3 & $\begin{array}{l}\text { RSD } \\
(\%)\end{array}$ \\
200 & $79.41 \pm 3.45$ & 4.34 & $93.8 \pm 1.63$ \\
2,000 & $90.13 \pm 2.74$ & 3.04 & $95.34 \pm 2.47$ \\
\hline
\end{tabular}

Abbreviations: $\mathrm{Cs}$, cyclosporine $\mathrm{A} ; \mathrm{SD}$, standard deviation; RSD, relative standard deviation.

Table 2 Intraday and interday accuracy and precision of CsA in rat whole blood sample at $50 \mathrm{ng} / \mathrm{mL}, 200 \mathrm{ng} / \mathrm{mL}, \mathrm{and} 2,000 \mathrm{ng} / \mathrm{mL}$ concentration levels

\begin{tabular}{|c|c|c|c|c|c|c|}
\hline \multirow{2}{*}{$\begin{array}{l}\text { CsA concentration } \\
(\mathrm{ng} / \mathrm{mL})\end{array}$} & \multicolumn{3}{|l|}{ Intraday $(n=6)$} & \multicolumn{3}{|l|}{ Interday $(n=18)$} \\
\hline & $\begin{array}{l}\text { Concentration measured } \\
\text { (mean } \pm \mathrm{SD}, \mathrm{ng} / \mathrm{mL})\end{array}$ & $\begin{array}{l}\text { Accuracy } \\
\text { (\%) }\end{array}$ & $\begin{array}{l}\text { Precision } \\
\text { (\%) }\end{array}$ & $\begin{array}{l}\text { Concentration measured } \\
\text { (mean } \pm \mathbf{S D}, \mathrm{ng} / \mathrm{mL} \text { ) }\end{array}$ & $\begin{array}{l}\text { Accuracy } \\
\text { (\%) }\end{array}$ & $\begin{array}{l}\text { Precision } \\
(\%)\end{array}$ \\
\hline 50 & $49.29 \pm 1.36$ & -1.42 & 2.76 & $45.17 \pm 1.90$ & -9.66 & 4.21 \\
\hline 200 & $196.94 \pm 3.79$ & -1.53 & 1.92 & $\mid 87.31 \pm 6.22$ & -6.34 & 3.32 \\
\hline 2,000 & $\mathrm{I}, 920.37 \pm 4 \mathrm{I} .08$ & -3.98 & 2.14 & $1,930.56 \pm 69.52$ & -3.47 & 3.6 \\
\hline
\end{tabular}

Abbreviations: CsA, cyclosporine A; SD, standard deviation.

Table 3 The stability of CsA in rat whole blood sample at $50 \mathrm{ng} / \mathrm{mL}, 200 \mathrm{ng} / \mathrm{mL}$, and 2,000 ng/mL concentration levels ( $\mathrm{n}=6$ )

\begin{tabular}{|c|c|c|c|c|}
\hline Stability & $\begin{array}{l}\text { Concentration } \\
(\mathrm{ng} / \mathrm{mL})\end{array}$ & $\begin{array}{l}\text { Concentration } \\
(\text { mean } \pm \mathrm{SD}, \mathrm{ng} / \mathrm{mL})\end{array}$ & $\begin{array}{l}\text { RSD } \\
\text { (\%) }\end{array}$ & $\begin{array}{l}\text { Accuracy } \\
(\%)\end{array}$ \\
\hline \multirow[t]{3}{*}{ At room temperature for 4 hours } & 50 & $50.8 I \pm 2.08$ & 4.09 & 1.62 \\
\hline & 200 & $205.4 I \pm 5.03$ & 2.45 & 2.70 \\
\hline & 2,000 & $2,073.24 \pm 37.41$ & 1.80 & 3.66 \\
\hline \multirow[t]{3}{*}{ Posttreatment for 24 hours at $4^{\circ} \mathrm{C}$} & 50 & $49.7 \pm 1.95$ & 3.91 & -0.59 \\
\hline & 200 & $|98.58 \pm 9.6|$ & 4.84 & -0.71 \\
\hline & 2,000 & $2,117.11 \pm 59.26$ & 2.79 & 5.85 \\
\hline \multirow[t]{3}{*}{ After three freeze-thaw cycles } & 50 & $49.29 \pm 1.21$ & 2.46 & $-1.4 \mid$ \\
\hline & 200 & $201.11 \pm 12.49$ & 6.21 & 0.56 \\
\hline & 2,000 & $2,046.22 \pm 36.05$ & 1.76 & 2.31 \\
\hline \multirow[t]{3}{*}{ At $-20^{\circ} \mathrm{C}$ for 30 days } & 50 & $49.72 \pm 2.45$ & 4.52 & -0.55 \\
\hline & 200 & $194.72 \pm 8.47$ & 4.35 & -2.64 \\
\hline & 2,000 & $1,952.26 \pm 67.14$ & 3.44 & -2.39 \\
\hline
\end{tabular}

Abbreviations: CsA, cyclosporine A; SD, standard deviation; RSD, relative standard deviation.

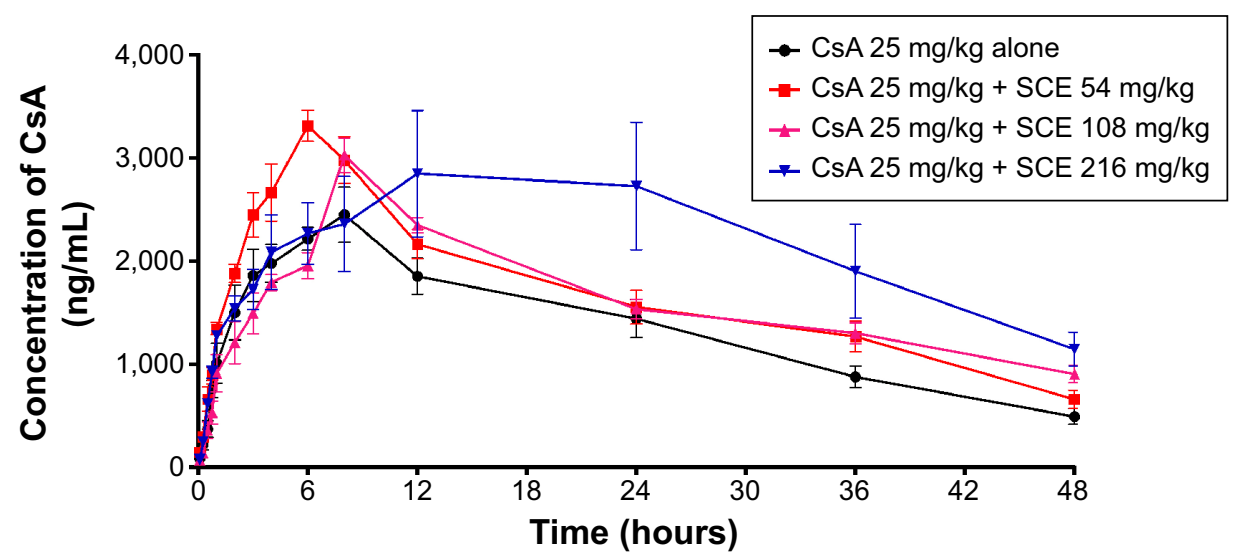

Figure 4 Whole blood concentration-time curves of CsA after a single oral dose of CsA $(25 \mathrm{mg} / \mathrm{kg})$ to rats with and without an oral dose of $54 \mathrm{mg} / \mathrm{kg}$, $108 \mathrm{mg} / \mathrm{kg}$, and $216 \mathrm{mg} / \mathrm{kg} \mathrm{SCE}$, respectively.

Note: Each point represents the mean \pm SD $(n=6)$.

Abbreviations: CsA, cyclosporine A; SCE, Schisandra chinensis extract; SD, standard deviation. 
Table 4 Pharmacokinetic parameters of CsA after a single oral dose of CsA $(25 \mathrm{mg} / \mathrm{kg})$ to rats with and without an oral dose of $54 \mathrm{mg} / \mathrm{kg}, 108 \mathrm{mg} / \mathrm{kg}$, and $216 \mathrm{mg} / \mathrm{kg}$ SCE, respectively

\begin{tabular}{|c|c|c|c|c|}
\hline \multirow[t]{2}{*}{ Parameter } & \multirow{2}{*}{$\begin{array}{l}\text { CsA }(25 \mathrm{mg} / \mathrm{kg}) \\
\text { alone }\end{array}$} & \multicolumn{3}{|l|}{ Dose of SCE } \\
\hline & & $54 \mathrm{mg} / \mathrm{kg}$ & $108 \mathrm{mg} / \mathrm{kg}$ & $216 \mathrm{mg} / \mathrm{kg}$ \\
\hline$T_{\max }(\mathrm{h})$ & $6.33 \pm 1.50$ & $6.8 \pm 1.10$ & $8.67 \pm 1.63$ & $13.5 \pm 7.55^{*}$ \\
\hline$C_{\max }(\mathrm{ng} / \mathrm{mL})$ & $2,608 \pm 585.89$ & $3,456.674 \pm 25$ I. $89 *$ & $3,026.806 \pm 409.6 I$ & $3,286.45 \pm I, 4 I 8.4 I$ \\
\hline$t_{1 / 2}(\mathrm{~h})$ & $19.92 \pm 6.43$ & $29.66 \pm 14.27$ & $28.44 \pm 9.00$ & $34.94 \pm 12.67 *$ \\
\hline $\mathrm{Vd} / \mathrm{F}(\mathrm{L} / \mathrm{kg})$ & $11.69 \pm 3.46$ & $10.00 \pm 1.42$ & $11.66 \pm 1.94$ & $18.54 \pm 5.32 *$ \\
\hline $\mathrm{CL} / \mathrm{F}(\mathrm{L} / \mathrm{h} / \mathrm{kg})$ & $0.4 I \pm 0.09$ & $0.27 \pm 0.11 *$ & $0.29 \pm 0.06$ & $0.22 \pm 0.14^{* *}$ \\
\hline$A \cup C_{0-t}(n g h / m L)$ & $65,0|8.08 \pm| 2,87 \mid .89$ & $85,865.0 I \pm 15,358.46$ & $75,006 . I I \pm 6,7 \mid 0.78$ & $94,184.06 \pm 40,369.06 *$ \\
\hline$A \cup C_{0-\infty}(\mathrm{ng} \mathrm{h} / \mathrm{mL})$ & $82,85|.36 \pm| 6,6 \mid 5.30$ & $132,564.2 \pm 50,934.74$ & ||$|4,030.90 \pm 2|, 573.65$ & $173,777.70 \pm 95,727.64^{*}$ \\
\hline $\mathrm{MRT}_{0-\mathrm{t}}(\mathrm{h})$ & $|8.9| \pm|.4|$ & $19.61 \pm 1.78$ & $20.73 \pm 1.36$ & $21.44 \pm 3.07$ \\
\hline $\mathrm{MRT}_{0-\infty}(\mathrm{h})$ & $31.96 \pm 8.83$ & $43.72 \pm 19.15$ & $44.06 \pm 11.84$ & $54.43 \pm 9.90 *$ \\
\hline
\end{tabular}

Notes: Data are the mean $\pm S D(n=6)$. $* P<0.05$ significantly different when compared with $C s A$ alone group. $* * P<0.01$ significantly different when compared with $C s A$ alone group.

Abbreviations: $\mathrm{Cs} A$, cyclosporine $\mathrm{A} ; \mathrm{SCE}$, Schisandra chinensis extract; $T_{\max }$, time to reach the maximum concentration; $C_{\max }$, maximum plasma concentration; $t_{1 / 2}$, half-life; $\mathrm{Vd} / \mathrm{F}$, apparent volume distribution; $\mathrm{CL} / \mathrm{F}$, clearance; $\mathrm{AUC}_{0-\mathrm{t}}$, area under the plasma concentration-time curve from time zero to last sampling time; $\mathrm{AUC}_{0-\infty}$, area under the plasma concentration-time curve from time zero to infinity; $\mathrm{MRT}_{0-\mathrm{t}}$, mean residence time from time zero to last sampling time; $\mathrm{MRT}_{0-\infty}$, mean residence time from time zero to infinity.

mean residence time was enhanced by 1.7 -fold when CsA was coadministered with SCE at dose of $216 \mathrm{mg} / \mathrm{kg}$.

\section{Effect of SCE on CsA-induced changes in the parameters of renal function within serum}

Serum $\mathrm{Cr}$ and BUN are biomarkers for kidney function. As shown in Figure 5, the serum $\mathrm{Cr}$ and BUN levels in rats treated with vehicle group were not statistically different when compared with the control group. The treatment of rats on low salt diet with $25 \mathrm{mg} / \mathrm{kg}$ CsA for 28 days continuously caused significant increases in serum $\mathrm{Cr}$ and $\mathrm{BUN}$ when compared with the vehicle group $(P<0.001)$. However, the CsA-induced increase in serum $\mathrm{Cr}$ and BUN levels was abolished when rats were treated concurrently with $54 \mathrm{mg} / \mathrm{kg}$ and $108 \mathrm{mg} / \mathrm{kg}$ SCE (Figure 5).

\section{Effect of SCE on CsA-induced changes in the parameters of oxidative stress within the kidney}

Lipid peroxidation as an index of oxidative stress was determined by assaying the MDA product levels by means
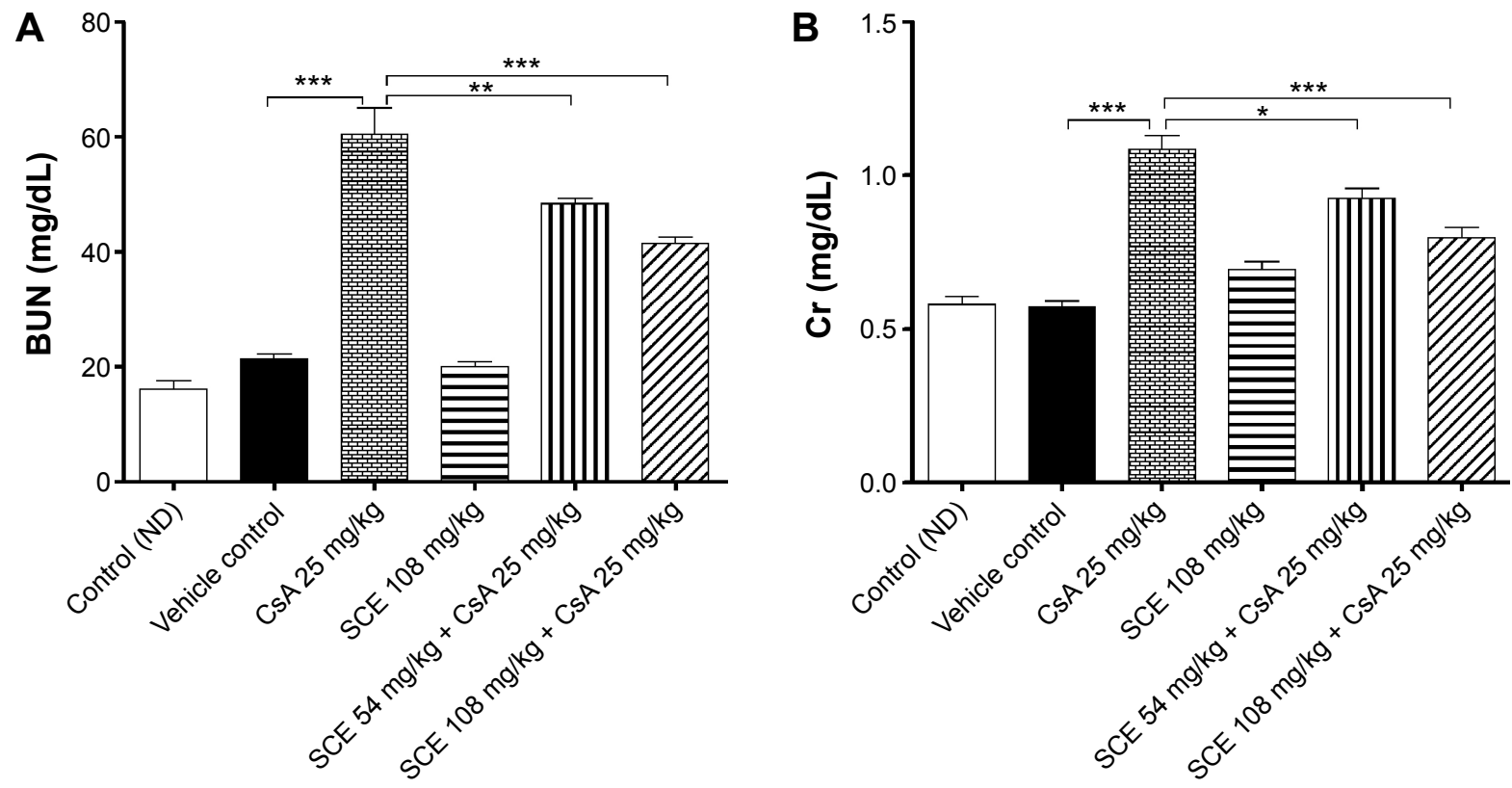

Figure 5 Effect of SCE on cyclosporine A (CsA)-induced nephrotoxicity in BUN (A) and $\mathrm{Cr}(\mathbf{B})$ levels in serum of different experimental groups.

Notes: Data were analyzed by one-way ANOVA and presented as mean $\pm S D(n=6)$. $* P<0.05, * * P<0.01$, and $* * * P<0.001$.

Abbreviations: SCE, Schisandra chinensis extract; BUN, blood urea nitrogen; Cr, creatinine; ANOVA, analysis of variance; SD, standard deviation; ND, normal diet. 
of the thiobarbituric acid test. ${ }^{24}$ As shown in Figure 6A, lipid peroxidation was increased significantly more in the kidney of rats administered with CsA ( $25 \mathrm{mg} / \mathrm{kg}$ ) for 28 days than in the kidney of rats from the vehicle group $(P<0.05)$. A concomitant treatment with SCE at doses of $54 \mathrm{mg} / \mathrm{kg}$ and $108 \mathrm{mg} / \mathrm{kg}(P<0.05$ and $P<0.001$, respectively) significantly prevented this increase. When compared with the CsA-only treatment group, the levels of thiobarbituric acid-reacting substance generation seemed to decreased by $22.34 \%$ and
$31.63 \%$ when SCE was administered at doses $54 \mathrm{mg} / \mathrm{kg}$ and $108 \mathrm{mg} / \mathrm{kg}$, respectively. As shown in Figure 6B, there was also a significant reduction in CAT activity levels after CsA treatment when compared with the vehicle group $(P<0.001)$. Treatment with SCE, on the other hand, showed significant improvement in CAT activity, which increased by $15.61 \%$ and $23.42 \%$ when administered with a dose of $54 \mathrm{mg} / \mathrm{kg}$ and $108 \mathrm{mg} / \mathrm{kg}$, respectively. Results obtained on the levels of GSH-Px activity in rats, which were treated with CsA,
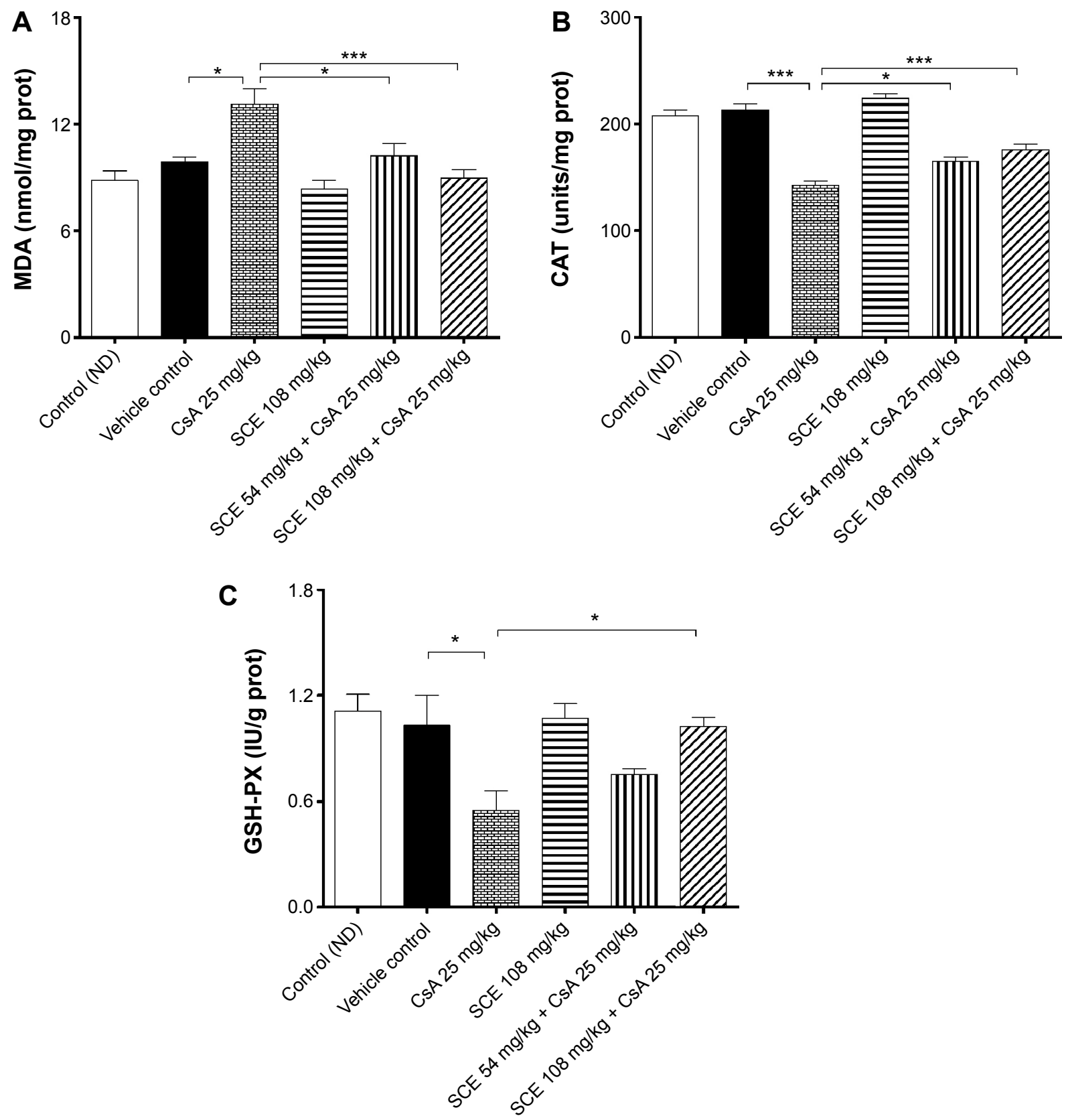

Figure 6 Effect of SCE on cyclosporine A (CsA)-induced nephrotoxicity in MDA (A), CAT (B), and GSH-Px (C) in kidney of different experimental groups. Notes: Data were analyzed by one-way ANOVA and presented as mean \pm SD $(n=6) . * P<0.05, * * * P<0.001$.

Abbreviations: SCE, Schisandra chinensis extract; MDA, malondialdehyde; CAT, catalase; GSH-Px, glutathione peroxidase; ANOVA, analysis of variance; SD, standard deviation; ND, normal diet. 
showed that there was a significant reduction in the activity of GSH-Px within the kidney post-CsA treatment $(P<0.05$ versus vehicle group), but when SCE was used in combination with CsA, the GSH-Px activity increased $(P<0.05$ versus CsA group; Figure 6C).

\section{Effect of SCE on CsA-induced histopathological changes in kidney}

Histological evaluation was performed using H\&E and Masson's trichrome staining in order to demonstrate tubular necrosis and interstitial fibrosis inside the tubuli renales (Figure 7). To assess the degree of total tubular necrosis in H\&E-stained sections (Figure 7A-F), the scores of tubular damage, inflammatory cell infiltrate, and cell debris in tubular lumens were semiquantitatively analyzed. The total score of tubular necrosis (Figure 7G) was represented by summing up from six individual scores. Kidney sections from control group (Figure 7A) and vehicle-treated (Figure 7B) group showed unremarkably normal histology. Those treated with CsA, however, showed histopathological changes in the renal cortex in the form of dilation of the tubules, severe vacuolation of the tubular cells, and an inflammatory cells infiltrate (13.20 \pm 4.11 versus vehicle control, $P<0.001)$. It was interesting to note that kidneys isolated from those rats, which were subject to the concomitant administration of SCE at doses of $54 \mathrm{mg} / \mathrm{kg}$ and $108 \mathrm{mg} / \mathrm{kg}$ alongside CsA, revealed attenuation of the tubular structural damage and massive inflammatory cells infiltrate that could otherwise be seen in the absence of SCE $(8.80 \pm 4.54,7.40 \pm 4.20$ versus 13.20 $4.11, P<0.05, P<0.01$, respectively; Figure 7E and F). Furthermore, kidney sections treated with SCE alone showed normal architecture (Figure 7D), which indicated that SCE by itself does not cause renal damage.

Masson's trichrome staining (Figure 8) demonstrated that renal fibrosis was significantly increased in rats given CsA compared with vehicle group $(0.252 \pm 0.07$ versus $0.137 \pm 0.04$, $P<0.001)$. Treatment with $54 \mathrm{mg} / \mathrm{kg}$ and $108 \mathrm{mg} / \mathrm{kg} \mathrm{SCE}$ significantly decreased the renal fibrosis area in CsA-treated rats $(0.175 \pm 0.05$ and $0.122 \pm 0.05$ versus $0.252 \pm 0.07$, respectively, $P<0.001)$.

\section{SCE protects against CsA-associated rise in 4-HNE}

It has been appreciated that the pathogenic effect of toxic responses in the kidney can be attributed mainly to the generation of oxidative radicals. 4-HNE, a product of lipid peroxidation, ${ }^{25}$ was detected using Western blot and immunohistochemical techniques (Figure 9). Western blot was used to analyze for the presence of 4-HNE adducts to protein following a 28-day exposure to CsA. The data showed that 4-HNE adduction was increased by 1.6 -fold with CsA treatment when compared to tissue that was treated in the vehicle group $(P<0.001)$. SCE has been reported to be a potent antioxidant, that is primarily used to treat kidney and liver disease. Consequently, when $54 \mathrm{mg} / \mathrm{kg}$ and $108 \mathrm{mg} / \mathrm{kg} \mathrm{SCE}$ were coadministered with


H\&E staining
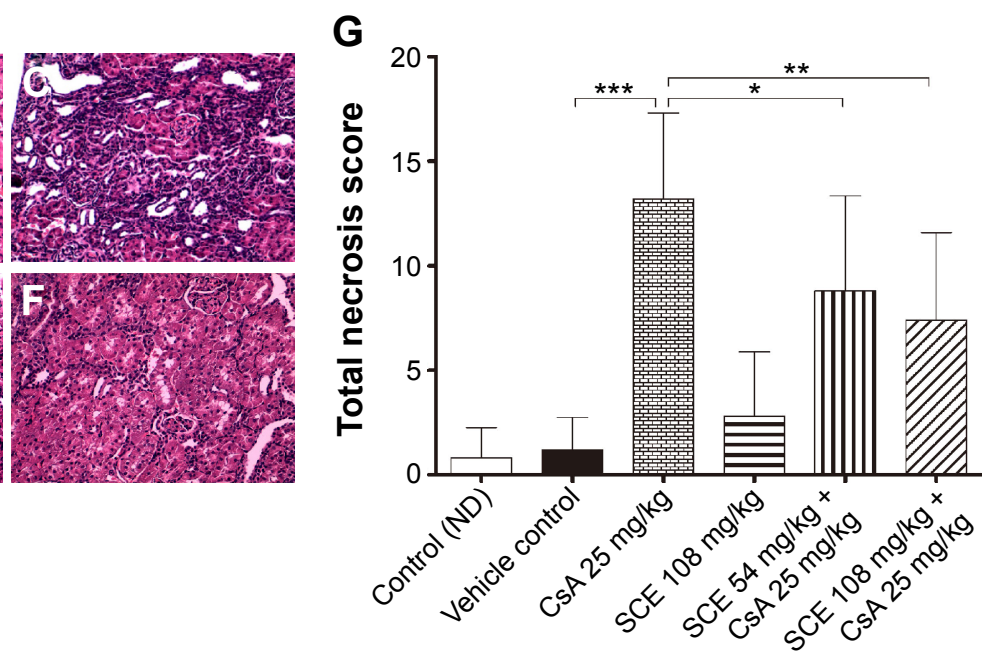

Figure 7 Photomicrographs $(\times 200, \mathrm{H} \& \mathrm{E})$ of renal tubules showing progressive stages of tubular necrosis and respective necrosis score.

Notes: Twelve random sections $(\times 200)$ from each kidney were examined, and a score from 0 to 3 was given to the tubular profile according to the following arbitrary scale: the damage affecting no $>5 \%$ of the field was scored 0 ; mild damage affecting $5 \%-25 \%$ of the field was scored I; moderate damage affecting $25 \%-75 \%$ of the field was scored 2; and severe damage exceeding $75 \%$ of the field was scored 3 . All 12 scores were added to give the total necrosis score for each kidney. (A) Control group. (B) Vehicle control. (C) $25 \mathrm{mg} / \mathrm{kg}$ CsA group. (D) $108 \mathrm{mg} / \mathrm{kg} \mathrm{SCE}$ group. (E) $54 \mathrm{mg} / \mathrm{kg} \mathrm{SCE}+25 \mathrm{mg} / \mathrm{kg}$ CsA group. (F) $108 \mathrm{mg} / \mathrm{kg}$ SCE $+25 \mathrm{mg} / \mathrm{kg}$ CsA group. (G) Semiquantitative scores revealed that the scores of total tubular necrosis were significant in the CsA exposed but reduced by SCE. Data were analyzed by nonparameters and expressed as mean number in the high power field of each group (mean $\pm S D, n=6$ ). $* P<0.05, * * P<0.01$, and $* * * P<0.00 \mathrm{I}$.

Abbreviations: H\&E, hematoxylin-eosin; CsA, cyclosporine A; SCE, Schisandra chinensis extract; SD, standard deviation. 

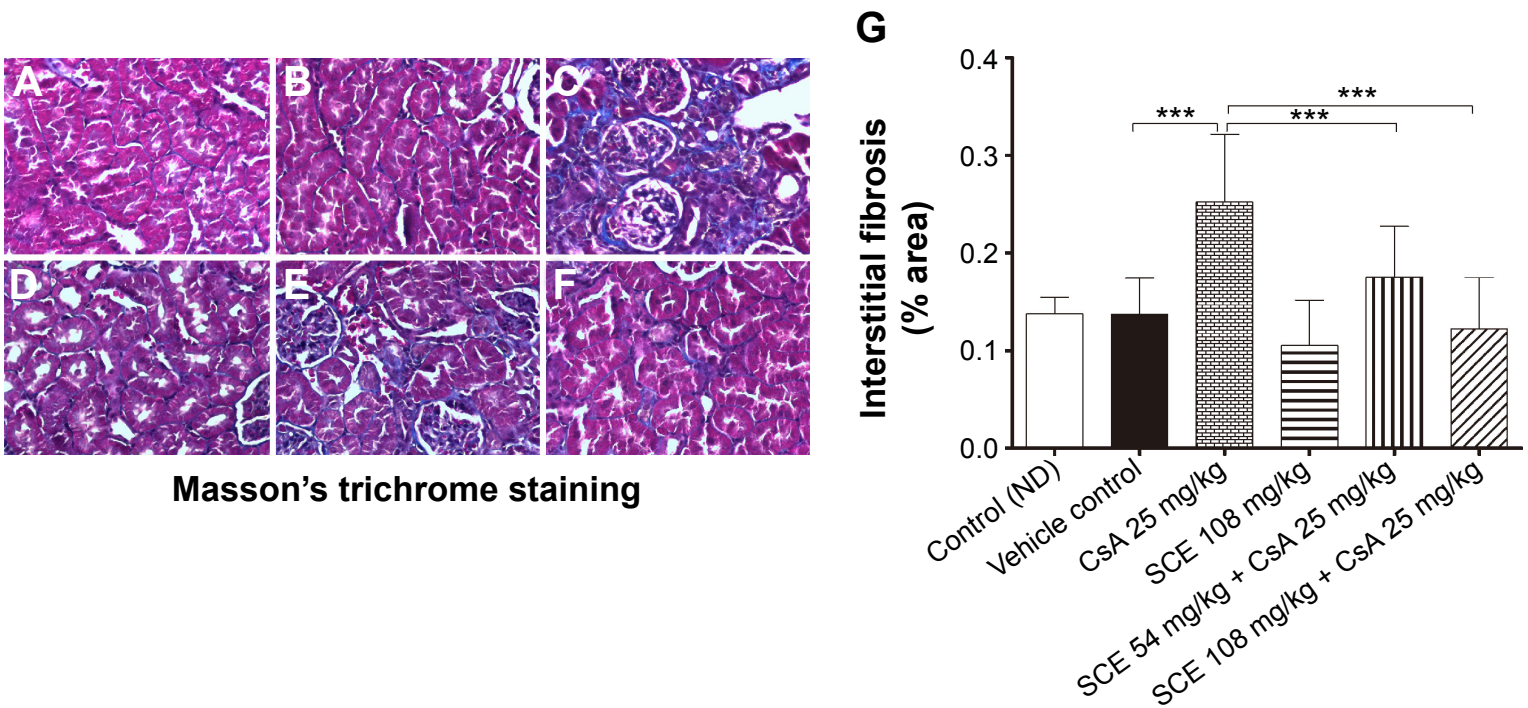

Figure 8 Tubulointerstitial fibrosis was detected by Masson's trichrome staining. Notes: Photomicrographs $(\times 200)$ of renal cortex obtain from Sprague Dawley rats for 28 days with (A) control group. (B) Vehicle control. (C) 25 mg/kg CsA group. (D) $108 \mathrm{mg} / \mathrm{kg} \mathrm{SCE}$ group. (E) $54 \mathrm{mg} / \mathrm{kg} \mathrm{SCE}+25 \mathrm{mg} / \mathrm{kg}$ CsA group. (F) $108 \mathrm{mg} / \mathrm{kg} \mathrm{SCE}+25 \mathrm{mg} / \mathrm{kg}$ CsA group. (G) Semiquantitative scores revealed that the percentage of stained area per high power filed of each group (mean $\pm S D, n=6$ ). *** $P<0.00$ I.

Abbreviations: CsA, cyclosporine A; SCE, Schisandra chinensis extract; SD, standard deviation.

CsA at separate time, oxidative stress improved, which could be seen by a significant decrease in 4-HNE adduction expression $(0.97 \pm 0.03$ and $0.86 \pm 0.10$, respectively, versus $1.60 \pm 0.07, P<0.001)$. Furthermore, the immunohistochemical analyses showed that compared to the vehicle treated group, treatment with CsA caused increases in 4 -HNE adduction expression by $20.42 \%(P<0.001)$. The concurrent administration of SCE reversed this increase in the immunohistochemical signal of 4-HNE adduction caused by CsA (Figure 9C and D).

\section{SCE promotes P-glycoprotein-mediated efflux in CsA nephropathy}

$\mathrm{P}$-gp is an adenosine triphosphate-binding cassette protein, which protects organs from the toxic effects of drugs and xenobiotics via an efflux mechanism. ${ }^{26}$ Located in the apical membrane of several barrier epithelia, including the intestine, renal epithelial cells, bile canalicula, and the brain capillary endothelial cells, P-gp's inhibition or induction may be responsible for drug interactions with phytomedicines. ${ }^{27}$ Changes in the levels of P-gp were measured in renal tissue by Western blotting assay. The results showed that P-gp level was intensively increased when rats were exposed to CsA when compared with vehicle control rats (Figure 10, $P<0.001)$. Interestingly, the administration of CsA in combination with either $54 \mathrm{mg} / \mathrm{kg}$ or $108 \mathrm{mg} / \mathrm{kg}$ SCE caused a remarkable upregulation of $\mathrm{P}$-gp expression. The expression was found to be increased by $9 \%$ when $108 \mathrm{mg} / \mathrm{kg} \mathrm{SCE}$ was administered, indicating significant promotion of $\mathrm{P}$-gpmediated efflux $(P<0.001)$.

\section{Effect of SCE on HO-I and Nrf2 expressions in renal tissues}

There is sufficient evidence supporting the protective role of the Nrf2-mediated pathway against oxidative stress and inflammation. ${ }^{28}$ Recent research has shown that Nrf2 has multiple functions, including acute and transient stress responses to oxidative insults. ${ }^{29} \mathrm{HO}-1$ gene expression is mainly regulated by the $\mathrm{Nrf} 2$ antioxidant response element (ARE) pathway, and induction of this enzyme protects cells from injury and death caused by oxidative stress. ${ }^{30} \mathrm{Nrf} 2$ expression was found to have increased post-CsA administration, paralleling the enhanced antioxidant capacity, but surprisingly not the inflammatory changes in renal tissues. Oxidative stress, ischemia reperfusion injury, cytokines, nitric oxide, and bacterial lipopolysaccharides increase the expression of HO-1. ${ }^{31,32}$ As is shown in Figure 10, low levels of Nrf2 and HO-1 were expressed in the control group and vehicle group. The expression of Nrf2 was significantly higher in the CsA and SCE groups when compared with the vehicle group $(P<0.001)$. Furthermore, expression of HO-1 was also significantly increased following CsA treatment $(P<0.001)$. When exposed to concomitant administration of SCE along with CsA, the increase in Nrf2 and HO-1 expression levels was higher than the increase found in the CsA only group $(P<0.001)$. In particular, it can be deduced 

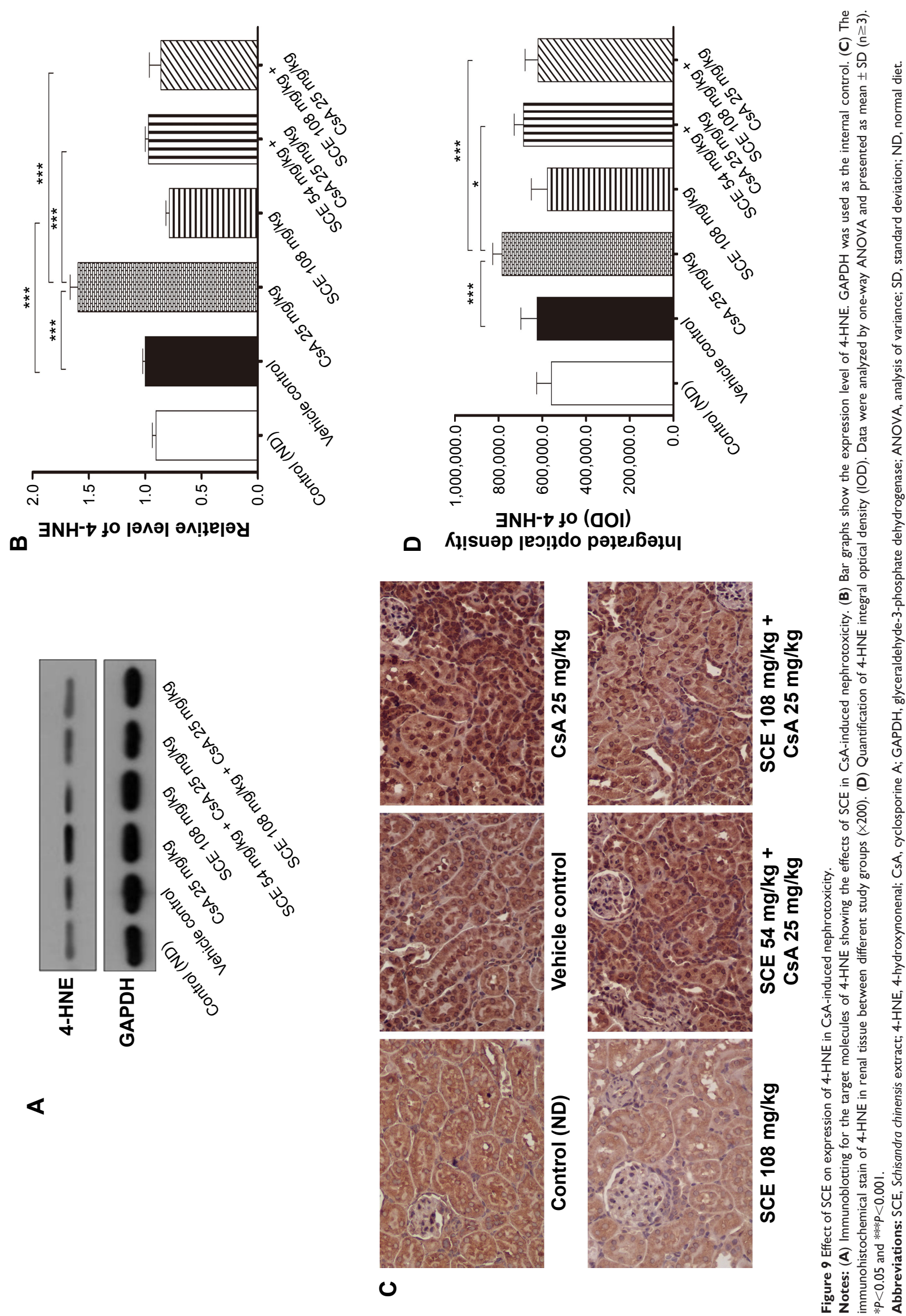
A

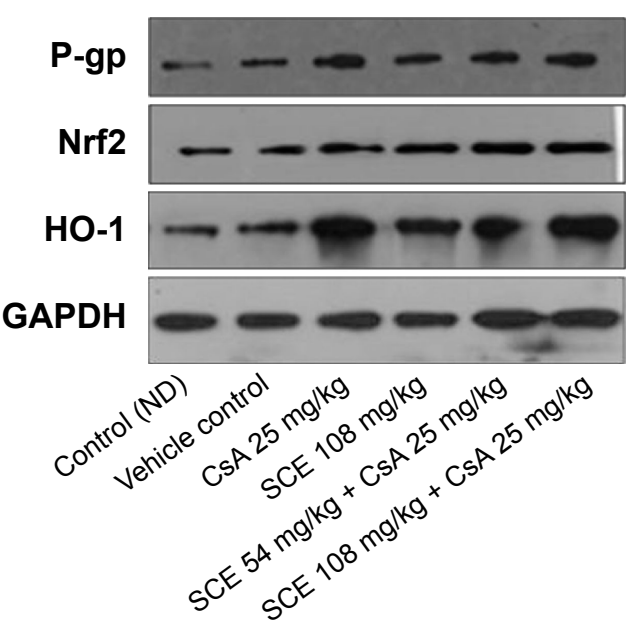

\section{C}

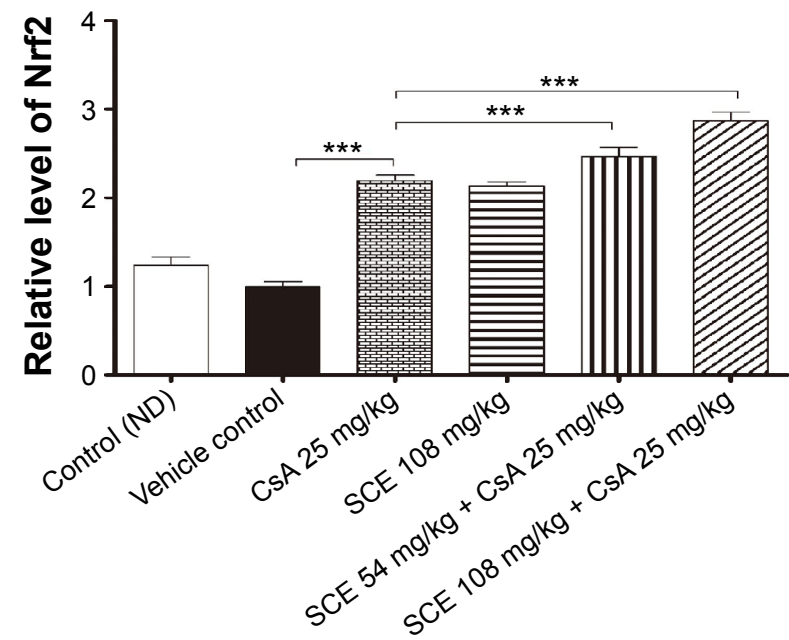

B

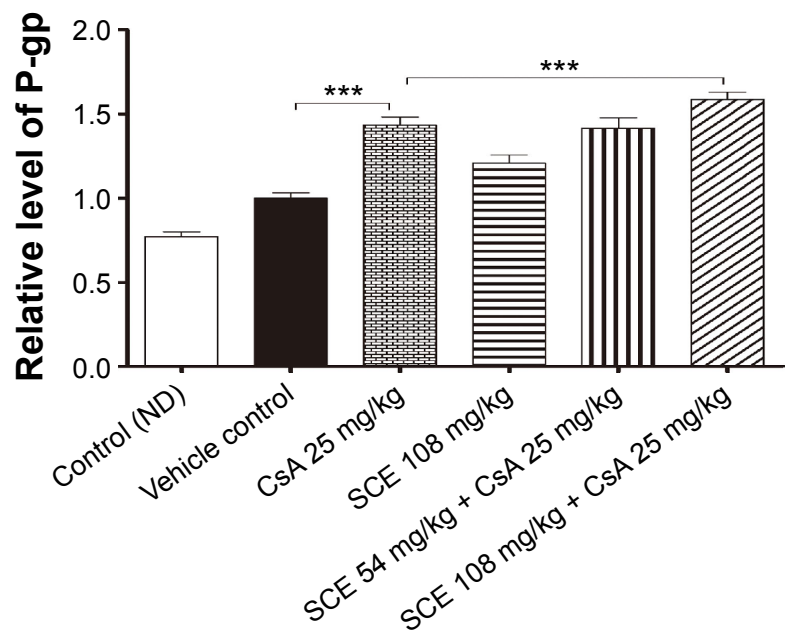

D

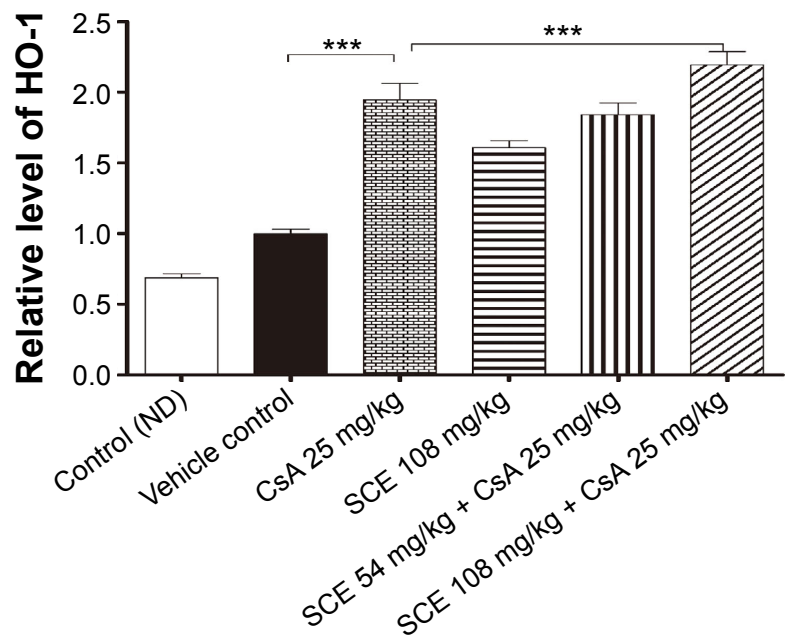

Figure 10 Effect of SCE on expression of P-gP, Nrf2, and HO-I in CsA-induced nephrotoxicity.

Notes: (A) Immunoblotting for the target molecule of P-gp, Nrf2, and HO-I showing the effects of SCE in CsA-induced nephrotoxicity. (B-D) Bar graphs show the expression levels of P-gp, Nrf2, and HO-I. GAPDH was used as the internal control. Data were analyzed by one-way ANOVA and presented as mean \pm SD ( $\mathrm{n} \geq 3$ ). $* * * P<0.001$.

Abbreviations: SCE, Schisandra chinensis extract; P-gp, P-glycoprotein; Nrf2, nuclear factor erythroid 2-related factor 2; HO-I, heme oxygenase I; CsA, cyclosporine A; GAPDH, glyceraldehyde-3-phosphate dehydrogenase; ANOVA, analysis of variance; SD, standard deviation; ND, normal diet.

that the increase in the expression of HO-1 during CsA treatment may be the defense mechanism counteracting CsA toxicity. In this study, we found that SCE attenuated renal injury induced by CsA supporting the possibility that HO-1 induction might play an important protective role against the CsA mediated renal damage in a Nrf2dependent manner.

\section{SCE decreases the expression of} apoptosis-related proteins cleaved

\section{caspase 3 and Bax in CsA nephropathy}

CsA is known to cause increased apoptosis of renal cells. Interestingly, apoptosis plays a central role not only in the physiological processes of kidney growth and remodeling but also in various human renal diseases and drug-induced nephrotoxicity, including the one induced by $\mathrm{CsA} .{ }^{33}$ Here, we evaluated whether SCE treatment suppressed the expression of apoptotic markers, Bax, and cleaved caspase 3 in CsA-induced nephropathy. As is shown in Figure 11A-C, increased cleaved caspase 3 and Bax expression was noted in the CsA group when compared with the vehicle control group (2.36 \pm 0.07 versus $1.00 \pm 0.07,2.36 \pm 0.06$ versus $1.00 \pm 0.03$, $P<0.001$, respectively). Furthermore, a more significant decrease in the expression of both cleaved caspase 3 and Bax was observed after concomitant administration of either $54 \mathrm{mg} / \mathrm{kg}$ or $108 \mathrm{mg} / \mathrm{kg} \mathrm{SCE}$ in comparison with when SCE was not administered with CsA $(2.10 \pm 0.08,1.59 \pm 0.08$ versus $2.36 \pm 0.07$ and $0.78 \pm 0.02,0.66 \pm 0.04$ versus $2.36 \pm 0.06$, 

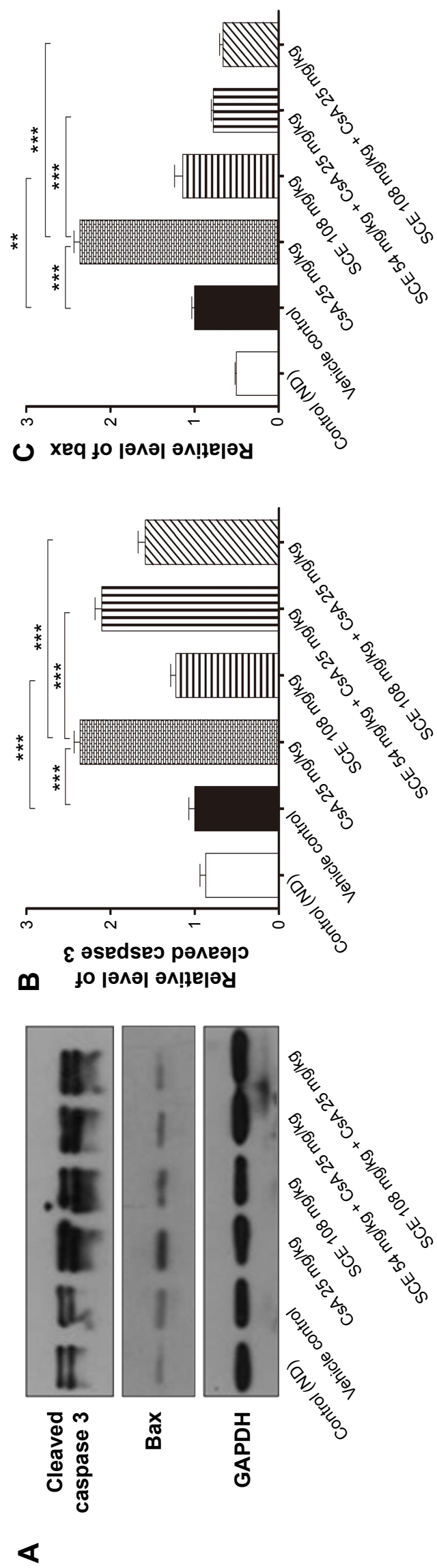
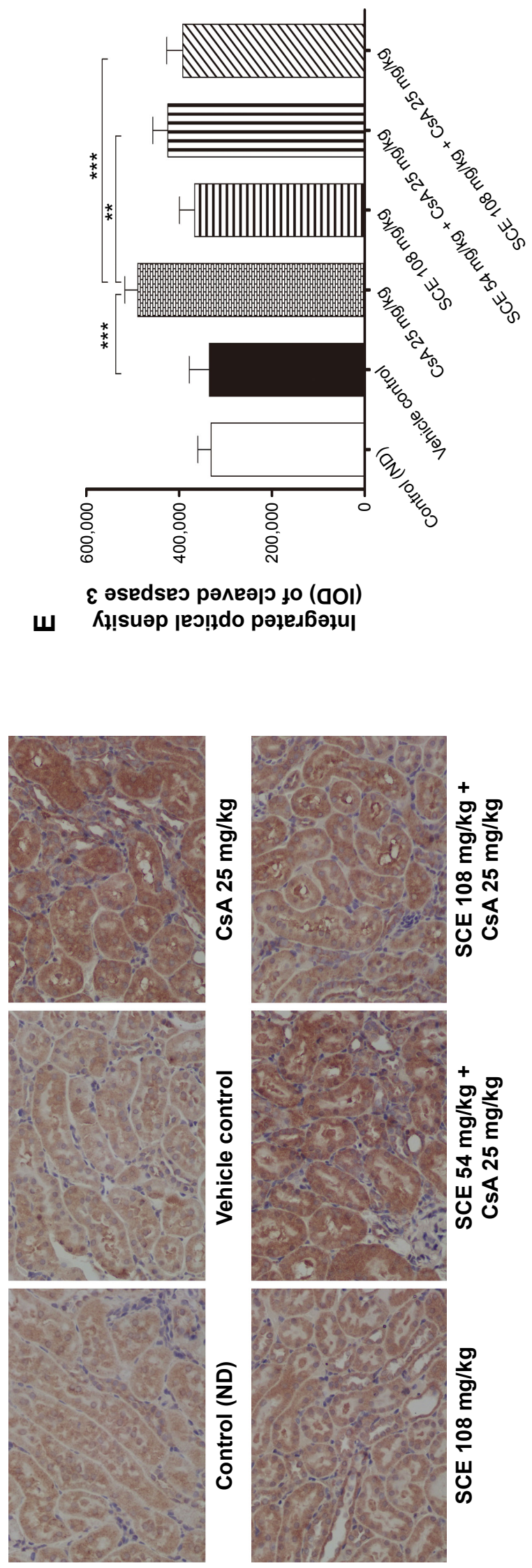

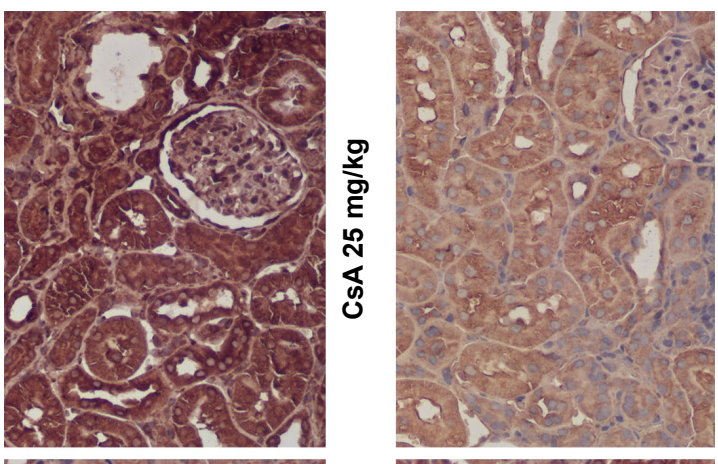

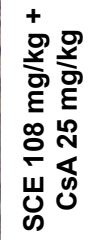
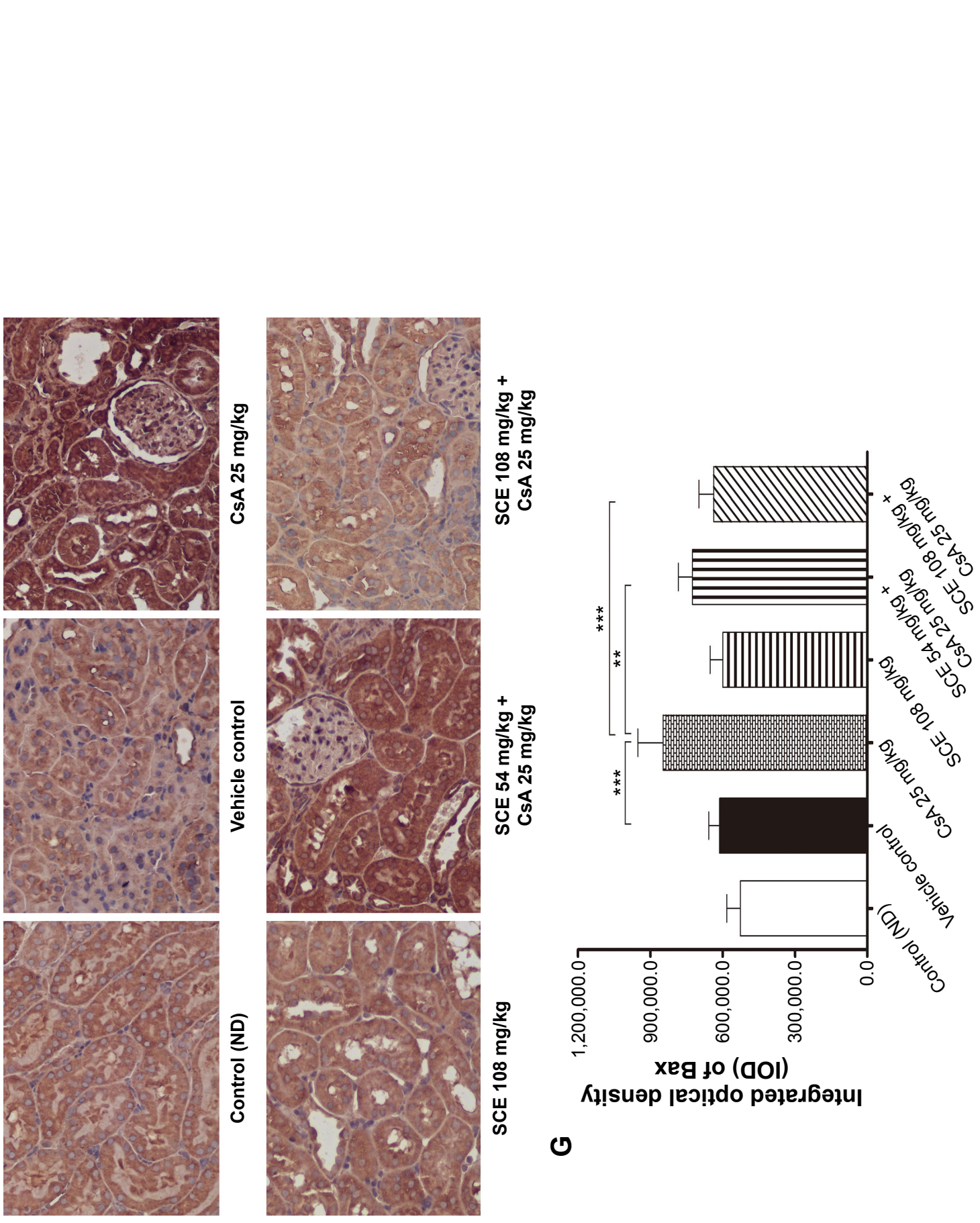

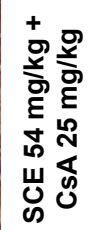
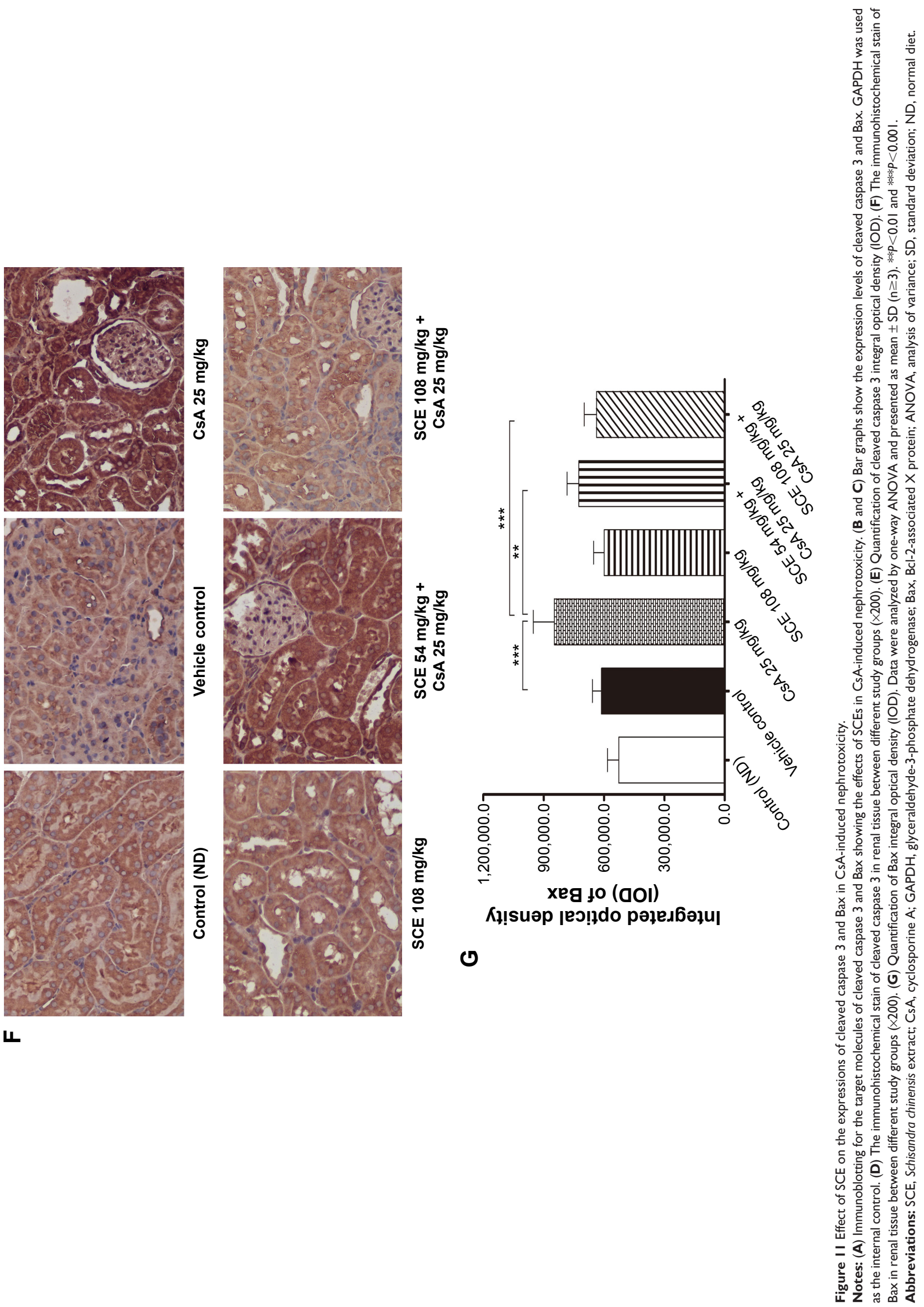

ᄂ 
$P<0.001$, respectively). At the same time, no significant differences were observed in renal cleaved caspase 3 between control and vehicle group. In contrast, however, Bax expression was found to be slightly upregulated in the vehicle group when compared with the control group. These results were used to credit the low salt diet for the possible acceleration in renal cell apoptosis rate in rats. Furthermore, as can be seen in Figure 11D-G, a significant elevation in cleaved caspase 3 and Bax expression was observed in the CsA-treated group when compared with vehicle group. This elevation was found to be suppressed by concomitant administration of SCE along with CsA.

\section{SCE prevents the upregulation of LC3A/B protein expression in CsA nephropathy}

The hallmark of autophagy is the presence of autophagosomes. These autophagosomes are characterized by double membrane bound compartments, which contain cytoplasmic material and/or organelles. ${ }^{34}$ Autophagy plays a complex role in promoting cell life and death. This process is essentially dependent on the cell type, the kind of stress experienced, and its duration. We tested, using Western blotting for ration of LC3-II (lipid form of LC3) and I (cytosolic form of LC3), whether CsA-induced autophagy is inhibited by SCE cotreatment. As can be seen in Figure 12, when compared with the vehicle control group, there was considerable upregulation of LC3-II/I after CsA treatment (2.9-fold, $P<0.001)$. When comparing with CsA group, cotreatment of rats with $54 \mathrm{mg} / \mathrm{kg}$ and $108 \mathrm{mg} / \mathrm{kg} \mathrm{SCE}$ decreased the expression level of LC3-II/I by $16.92 \%$ and $23.53 \%$, respectively $(P<0.001)$. Furthermore, immunohistochemical techniques were used to demonstrate that SCE inhibits autophagy during CsA treatment. As shown in Figure 12C and D, when compared with vehicle-treated animals, CsA treatment significantly increased positive signals staining of tubules at 28 days $(P<0.001)$. When $54 \mathrm{mg} / \mathrm{kg}$ and $108 \mathrm{mg} / \mathrm{kg} \mathrm{SCE}$ were coadministered with CsA, positive signals staining of tubules were found to be in a significantly lower quantity $(P<0.01$ and $P<0.001)$. These data suggest that SCE reduces CsAinduced autophagy.

\section{Discussion}

S. chinensis, one of the most important traditional herbal medicines, has been extensively used in coadministration with several drugs, more so than it has been used singly. The simultaneous use of herbal medicines with CsA has recently gained considerable attention as useful concomitants, particularly in reducing the adverse effects of CsA.
Numerous studies have demonstrated that the CsA-induced nephrotoxicity, which is characterized by decreased glomerular filtration rate and fibrosis, is a major cause of chronic renal disease in rat models and this can be applied to clinical practice as well..$^{35}$

The molecular mechanisms underlying CsA-induced nephrotoxicity remain poorly understood. To further elucidate the in vivo mechanisms, we analyzed the effect of different doses of SCE on the pharmacokinetics of CsA in rats. We found a higher blood concentration of CsA, with a longer half-life, when a series of single doses of SCE were administered in rats. These results are consistent with a previous study, where it had been demonstrated that the blood concentration of CsA in rats markedly increases after the administration of Wuzhi tablet (Schisandra sphenanthera extract). The inhibitory effect of the Wuzhi tablet ingredients on the activity of P-gp and CYP3A4 was deemed responsible for the formerly mentioned effects. ${ }^{36}$ Similarly, another study had also revealed that several constituents from $S$. chinensis could inhibit the activity of P-gp and CYP3A. ${ }^{37,38}$ In previous reports, Schisandra lignan extract was found to cause irreversible inhibition of CYP3A until this enzyme could be newly synthesized. ${ }^{39}$ Furthermore, CsA has also been shown to act as both substrate and inhibitor for CYP3A and P-gp. ${ }^{40}$ Previous research has also demonstrated the effect Wuzhi tablets have on the transport, metabolism, and pharmacokinetics of digoxin and midazolam (typical P-gp and CYP3A substrate). This in turn provides evidence to support that Wuzhi tablet has a direct inhibitory effect on the activity of P-gp and CYP3A. ${ }^{41}$ Therefore, a possible interaction between the strong inhibition of SCE on P-gp-mediated efflux and CYP3A-mediated metabolism of CsA could result in an increase in the systemic exposure to CsA. These results may provide more reliable experimental data and scientific explanations for its rational clinical application or related herb-drug interactions.

Additionally, we also demonstrated the ability of SCE to ameliorate CsA-induced nephrotoxicity in rat model experiment. In this study, we perused through the majority of published studies, which were based on the salt-depleted rat model, assessing CsA-induced nephrotoxicity. The salt-depleted rats underwent renal injury faster than rats on normal salt diet, and their kidneys showed morphological and pathological changes similar to those occurring in renal transplant patients. ${ }^{42}$ In agreement with previous studies, ${ }^{43-45}$ the present investigation revealed that administration of CsA results in deterioration of renal function as evidence by the marked elevation of serum urea and $\mathrm{Cr}$ levels. Furthermore, 


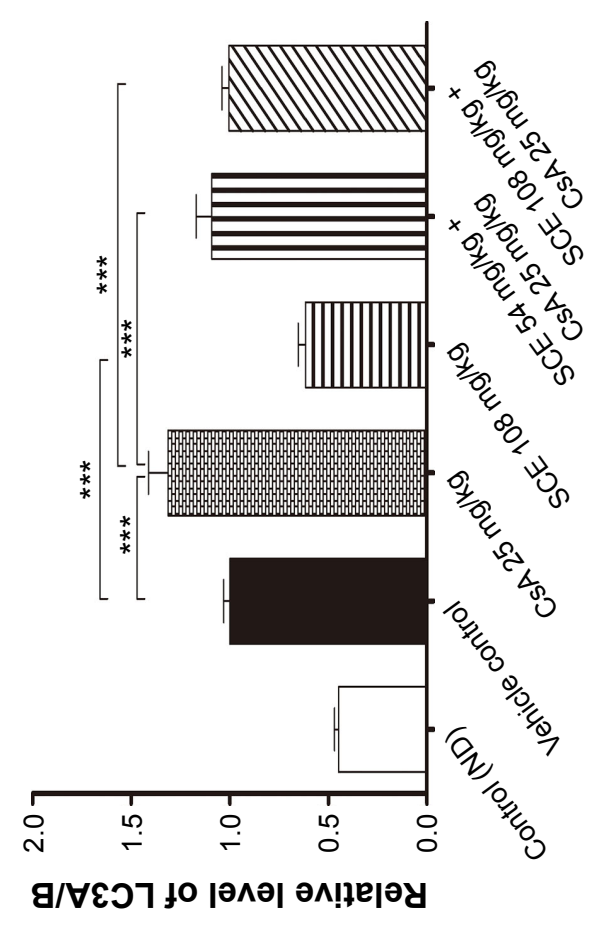

$\boldsymbol{m}$

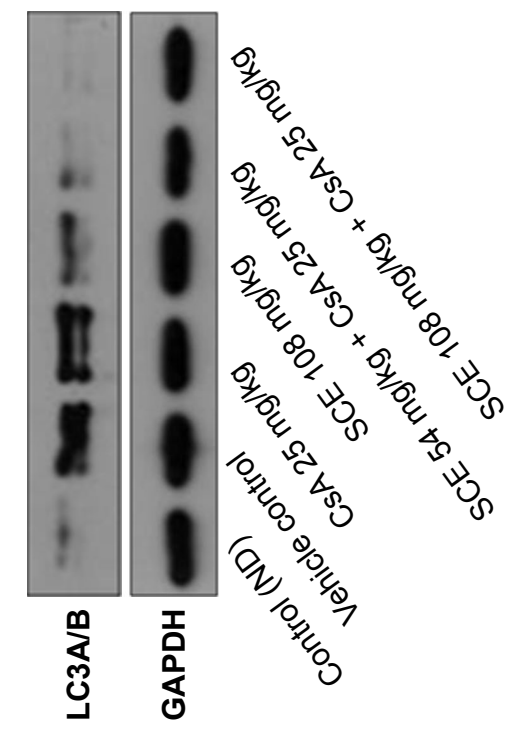

$\varangle$
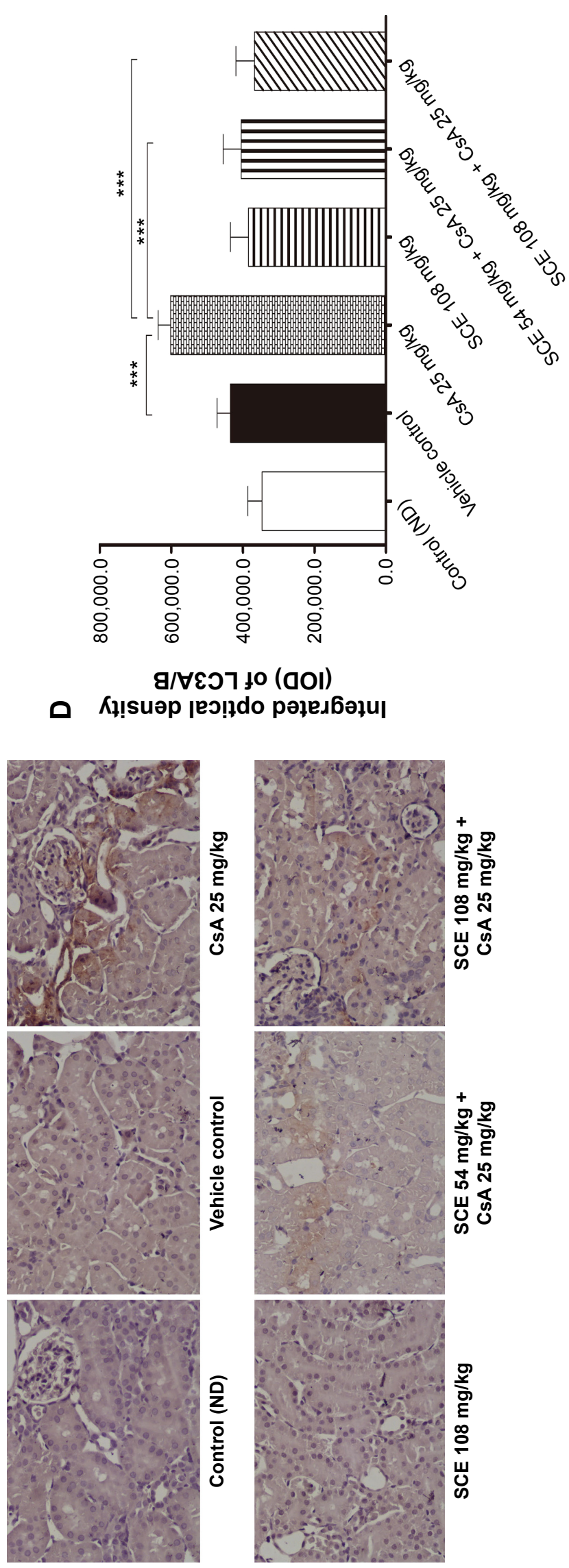

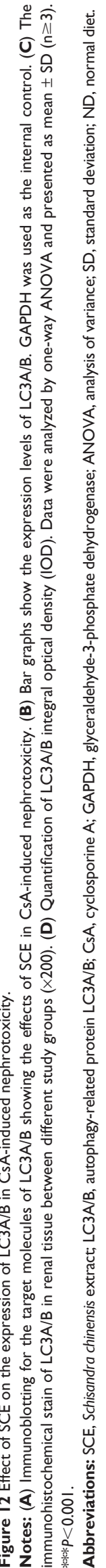


the development of CsA-induced renal dysfunction in the current investigation was accompanied by a rise in renal MDA levels along with a significant reduction in renal CAT activity and GSH-Px levels. Treatment with SCE reduced CsA-induced renal dysfunction, and this was demonstrated by the improvement in the markers of renal injury mentioned previously. These findings are in line with other studies, suggesting that oxidative stress plays a crucial part in the pathogenesis of CsA-induced nephrotoxicity. ${ }^{46-48} \mathrm{As}$ described previously, the renal functional status seems to be in close agreement with the histopathological data obtained using H\&E and Masson's trichrome staining. These data demonstrated tubular necrosis, vacuolation, and renal fibrosis in tubular cells of rats treated with CsA. It was revealed that the group coadministered with SCE showed less renal damage with fewer tubular cells affected, which were similar in appearance with the almost normal architecture observed in the vehicle group. The renoprotective mechanism of SCE is associated with attenuation of interstitial inflammation, fibrosis, apoptotic cell death, and oxidant stress.

CsA is known to increase ROS levels via two methods: 1) CsA treatment itself can reduce levels of components of the antioxidant defense system, thereby enhancing ROS levels in the kidney and 2) CsA-mediated production of transforming growth factor beta and angiotensin II can further enhance the level of ROS by activating nicotinamide adenine dinucleotide phosphate oxidase. ${ }^{49,50}$ Previous studies established that ROS production and oxidative stress are involved in CsA nephrotoxicity. ${ }^{35,46,51}$ This study supported our hypothesis that SCE had renal protective effects in CsA nephrotoxicity model, a well-established renal injury model. In this model, CsA-induced generation of ROS led to an increase in the expression of 4-HNE (a product of lipid peroxidation) and HO-1 (an inducible isoform in response to oxidative stress). $\mathrm{HO}-1$ is recognized as a protective gene in the kidney and is involved in the degradation of prooxidant heme. This results in the production of anti-inflammatory, antioxidant, and antiapoptotic metabolites. ${ }^{52}$ The finding that CsA treatment increased HO-1 expression in an Nrf2-dependent manner was consistent with and confirmed the findings of a previous report on rat kidney tubular epithelial cells and murine fibroblasts. ${ }^{28,31}$ Several studies revealed that some lignans isolated from fruits of $S$. chinensis, including schizandrin B, alpha-iso-cubebenol, and tigloylgomisin $\mathrm{H}$, activated Nrf2 pathway and consequently exhibited anti-inflammatory properties and potential liver cancer prevention abilities. ${ }^{53,54}$ It has not been determined whether SCE-induced Nrf2 signaling is required to counteract $\mathrm{CsA}$-induced nephrotoxicity.
Indeed, SCE can increase its expression through enhanced nuclear translocation to Nrf2 and subsequent activation of downstream antioxidant enzyme targets. Both basal and inducible expression of many of these antioxidant enzymes are regulated by Nrf2, a member of the cap 'n' collar family of basic leucine zipper transcription factors, through the antioxidant response element. ${ }^{55,56}$ Numerous comparative studies of the phenotypes of wild-type and Nrf2-disrupted mice have revealed the pivotal role of Nrf2 in protection against oxidant injuries: Nrf2-disrupted mice are much more susceptible to toxicity mediated by environmental chemicals and stresses than wild-type mice. ${ }^{28,57}$

The mechanism of renoprotection induced by SCE was further investigated. Apoptosis is an essential process in the development and tissue homeostasis of most multicellular organisms, and deregulation of apoptosis has been implicated in the pathogenesis of CsA-induced nephropathy. ${ }^{58}$ Apoptosis is initiated by two distinct pathways: an intrinsic pathway involving mitochondria and an extrinsic pathway leading to rapid recruitment of Fas-associated protein with death domain and caspase $8 .{ }^{59}$ Using immunoblotting, the expression of cleaved caspase 3 and Bax was found to be increased in rats' kidneys, which received CsA in this study, while SCE coadministration was also found to be able to attenuate the increase in these apoptotic factors. Hence, conclusion drawn from this result was that CsA can induce apoptosis in kidney by increasing cleaved caspase 3 and Bax expression. ${ }^{51}$ On the other hand, immunostaining for cleaved caspase 3 and Bax, markers of apoptosis, was significantly attenuated in rats treated with SCE. Therefore, it was inferred that SCE treatment was able to protect tubular cells against CsA-induced apoptosis by attenuating the increase in the activation of apoptosis factors. The apoptosis induced by CsA may develop through the intrinsic pathway because it not only promotes Bax aggregation and translocation to the mitochondria but also causes a caspase-dependent loss of mitochondrial membrane potential and activation of caspase 3. ${ }^{60,61}$ Apoptosis has been clearly witnessed in tubular and interstitial cells of transplanted patients with chronic cyclosporine nephrotoxicity. ${ }^{62}$ Tubular cell apoptosis has also been observed in animal and cell culture models. ${ }^{12}$ Apoptosis of different types of cells could lead to different outcomes, for instance, excessive apoptosis in tubular epithelial cells results in tubular atrophy and loss of functional mass, whereas inflammatory cells cleared away by apoptosis facilitates renal structure remodeling and functional recovery. ${ }^{63}$ More importantly, the effects of several lignan compounds, isolated from $S$. chinensis, on the antiapoptotic activity 
have been previously studied. Pretreatment with gomisin A from $S$. chinensis was also found to inhibit renal apoptosis through suppression of caspase 3 activity and elevation of serum tumor necrosis factor alpha, and this led to a decrease in the number of apoptotic cells. ${ }^{64,65}$ Taken together, these findings demonstrate that SCE causes reduction in excessive apoptosis and that it may play an important role in preventing the development of CsA nephropathy.

Autophagy is a process for degrading proteins, organelles, and recycling materials in response to cellular stress, and it is accompanied by progressive development of vesicle structures from autophagosomes. ${ }^{66}$ It has been recognized to play a critical role in removing both protein aggregates and damaged or excess organelles to maintain intracellular homeostasis and keep the cell healthy. However, excessive or inappropriate autophagy can also lead to cell death (autophagic cell death). Recent reports have demonstrated that CsA induces autophagy in human tubular cells and in vivo in rat kidneys, and it has been suggested that auotophagy serves as a protective mechanism against CsA toxicity. ${ }^{67}$ In this study, we evaluated whether CsA-induced autophagy caused renal injury and whether this could be attenuated by concomitant treatment with SCE. We found that the expression of LC3A/B was significantly increased post-CsA treatment. Concomitant administration of SCE reduced the expression of $\mathrm{LC} 3 \mathrm{~A} / \mathrm{B}$. Overall, the induction of protein aggregates by CsA treatment was decreased by SCE cotreatment, and this effect may contribute to a decrease in subsequent autophagosome formation in CsA nephropathy.

\section{Conclusion}

To summarize, whole blood concentrations of $\mathrm{CsA}$ in rats were significantly increased after cotreatment with SCE. SCE could increase the systemic exposure of CsA in rats due to the strong inhibitory effect of SCE on P-gp and CYP3A activity. At the same time, concomitant administration with SCE was found to be protective against CsA-induced renal nephrotoxicity. SCE administration led to reduction in lipid peroxidation, oxidative stress, apoptosis, and autophagy normally associated with CsA. SCE cotreatment prevented CsA-mediated inhibition of CAT and GSH-Px enzyme. Maintaining CAT and GSH-Px activity by administering SCE with CsA reduced ROS levels and oxidative stress. Subsequently, we demonstrated that the Nrf2 system plays a protective role in CsA-mediated renal fibrosis, and that HO-1 might make a major contribution to prevent renal dysfunction among Nrf2 target genes. Finally, it can be deduced from our study that renal damage caused by CsA leads to tubular cell apoptosis and autophagic cell death, and that SCE plays a protective role against CsA-induced renal injury by decreasing the induction of apoptotic factors and excessive autophagosomes. In conclusion, SCE may serve as an effective adjunct for a CsA-based immunosuppressive regimen to ameliorate CsA-induced nephrotoxicity. Most importantly, when they are used in combination, the adjustment of dose schedule for CsA should be taken into consideration to account for the effects of SCE on the pharmacokinetics of CsA. Based on the current findings, the therapeutic prospect of SCE for this purpose is recommended.

\section{Acknowledgment}

We thank the National Natural Science Foundation of China (grant no's 81102548 and 81473582) for financial support of this study.

\section{Disclosure}

The authors report no conflicts of interest in this work.

\section{References}

1. Grinyo JM, Cruzado JM. Cyclosporine nephrotoxicity. Transplant Proc. 2004;36(2):240S-242S.

2. Mariee AD, Abd-Ellah MF. Protective effect of docosahexaenoic acid against cyclosporine A-induced nephrotoxicity in rats: a possible mechanism of action. Ren Fail. 2011;33(1):66-71.

3. Tavares P, Fontes Ribeiro CA, Teixeira F. Cyclosporin effect on noradrenaline release from the sympathetic nervous endings of rat aorta. Pharmacol Res. 2003;47(1):27-33.

4. Tedesco D, Haragsim L. Cyclosporine: a review. J Transplant. 2012; 2012:230386.

5. Capasso G, Di Gennaro CI, Della Ragione F, et al. In vivo effect of the natural antioxidant hydroxytyrosol on cyclosporine nephrotoxicity in rats. Nephrol Dial Transplant. 2008;23(4):1186-1195.

6. Yoon HE, Lim SW, Piao SG, Song JH, Kim J, Yang CW. Statin upregulates the expression of klotho, an anti-aging gene, in experimental cyclosporine nephropathy. Nephron Exp Nephrol. 2012;120(4):E123-E133.

7. Lim SW, Hyoung BJ, Piao SG, Doh KC, Chung BH, Yang CW. Chronic cyclosporine nephropathy is characterized by excessive autophagosome formation and decreased autophagic clearance. Transplantation. 2012; 94(3):218-225.

8. Ciechomska IA, Gabrusiewicz K, Szczepankiewicz AA, Kaminska B. Endoplasmic reticulum stress triggers autophagy in malignant glioma cells undergoing cyclosporine A-induced cell death. Oncogene. 2013; 32(12):1518-1529.

9. Daly PJ, Docherty NG, Healy DA, McGuire BB, Fitzpatrick JM, Watson RWG. The single insult of hypoxic preconditioning induces an antiapoptotic response in human proximal tubular cells, in vitro, across cold storage. BJU Int. 2009;103(2):254-259.

10. Kasap B, Soylu A, Kuralay F, et al. Protective effect of Epo on oxidative renal injury in rats with cyclosporine nephrotoxicity. Pediatr Nephrol. 2008;23(11):1991-1999.

11. Sánchez-Pozos K, Lee-Montiel F, Pérez-Villalva R, et al. Polymerized type I collagen reduces chronic cyclosporine nephrotoxicity. Nephrol Dial Transplant. 2010;25(7):2150-2158.

12. Liu QF, Deng ZY, Ye JM, He AL, Li SS. Ginsenoside Rg1 protects chronic cyclosporin A nephropathy from tubular cell apoptosis by inhibiting endoplasmic reticulum stress in rats. Transplant Proc. 2015; 47(2):566-569. 
13. Mitic K, Popovska M, Pandilova M, Jovanovic R, Spasovski G, Nikolov V. The role of inflammation and apoptosis in cyclosporine $\mathrm{A}$ - induced gingival overgrowth. Bosn J Basic Med Sci. 2013;13(1):14-20.

14. Ahn TS, Kim DG, Hong NR, et al. Effects of Schisandra chinensis extract on gastrointestinal motility in mice. J Ethnopharmacol. 2015; 169:163-169.

15. Panossian A, Wikman G. Pharmacology of Schisandra chinensis Bail: an overview of Russian research and uses in medicine. J Ethnopharmacol. 2008;118(2):183-212.

16. Lee KH, Morris-Natschke S, Qian K, et al. Recent progress of research on herbal products used in traditional Chinese medicine: the herbs belonging to the divine husbandman's herbal foundation canon (Shen Nong Ben Căo Jing). J Tradit Complement Med. 2012;2(1): 6-26.

17. Wang B-L, Hu J-P, Sheng L, Chen H, Li Y. Chemical-pharmacokineticpharmacodynamic fingerprints of Schisandra chinensis alcoholic extract. Yao Xue Xue Bao. 2013;48(5):734-740.

18. Chun JN, Cho M, So I, Jeon JH. The protective effects of Schisandra chinensis fruit extract and its lignans against cardiovascular disease: a review of the molecular mechanisms. Fitoterapia. 2014;97: 224-233.

19. Bunel V, Antoine MH, Nortier J, Duez P, Stevigny C. Protective effects of schizandrin and schizandrin B towards cisplatin nephrotoxicity in vitro. J Appl Toxicol. 2014;34(12):1311-1319.

20. Zhang MZ, Liu M, Xiong M, Gong JB, Tan XY. Schisandra chinensis fruit extract attenuates albuminuria and protects podocyte integrity in a mouse model of streptozotocin-induced diabetic nephropathy. J Ethnopharmacol. 2012;141(1):111-118.

21. Chen P, Pang S, Yang N, et al. Beneficial effects of schisandrin B on the cardiac function in mice model of myocardial infarction. PLoS One. 2013;8(11):12.

22. Chun JN, Kim SY, Park EJ, et al. Schisandrin B suppresses TGF beta 1-induced stress fiber formation by inhibiting myosin light chain phosphorylation. J Ethnopharmacol. 2014;152(2):364-371.

23. He J-L, Zhou Z-W, Yin J-J, He C-Q, Zhou S-F, Yu Y. Schisandra chinensis regulates drug metabolizing enzymes and drug transporters via activation of Nrf2-mediated signaling pathway. Drug Des Devel Ther. 2015;9:127-146.

24. Ciarcia R, Damiano S, Fiorito F, et al. Hydrocortisone attenuates cyclosporin A-induced nephrotoxicity in rats. J Cell Biochem. 2012; 113(3):997-1004.

25. Hirose M, Yasui T, Okada A, et al. Renal tubular epithelial cell injury and oxidative stress induce calcium oxalate crystal formation in mouse kidney. Int J Urol. 2010;17(1):83-92.

26. Gu XS, Manautou JE. Regulation of hepatic ABCC transporters by xenobiotics and in disease states. Drug Metab Rev. 2010;42(3): 482-538.

27. Liang Y, Zhou Y, Zhang J, et al. Pharmacokinetic compatibility of ginsenosides and Schisandra Lignans in Shengmai-san: from the perspective of P-glycoprotein. PLoS One. 2014;9(6):12.

28. Shin DH, Park HM, Jung KA, et al. The NRF2-heme oxygenase-1 system modulates cyclosporin A-induced epithelial-mesenchymal transition and renal fibrosis. Free Radic Biol Med. 2010;48(8) 1051-1063.

29. Sykiotis GP, Habeos IG, Samuelson AV, Bohmann D. The role of the antioxidant and longevity-promoting Nrf2 pathway in metabolic regulation. Curr Opin Clin Nutr Metab Care. 2011;14(1):41-48.

30. Chapple SJ, Siow RC, Mann GE. Crosstalk between Nrf2 and the proteasome: therapeutic potential of Nrf2 inducers in vascular disease and aging. Int J Biochem Cell Biol. 2012;44(8):1315-1320.

31. Kang JS, Han MH, Kim GY, et al. Nrf2-mediated HO-1 induction contributes to antioxidant capacity of a Schisandrae fructus ethanol extract in C2C12 myoblasts. Nutrients. 2014;6(12):5667-5678.

32. Ryu EY, Park SY, Kim SG, et al. Anti-inflammatory effect of heme oxygenase-1 toward Porphyromonas gingivalis lipopolysaccharide in macrophages exposed to gomisins A, G, and J. J Med Food. 2011; 14(12):1519-1526.
33. Servais H, Ortiz A, Devuyst O, Denamur S, Tulkens PM, MingeotLeclercq MP. Renal cell apoptosis induced by nephrotoxic drugs: cellular and molecular mechanisms and potential approaches to modulation. Apoptosis. 2008;13(1):11-32.

34. Pallet N, Bouvier N, Legendre C, et al. Autophagy protects renal tubular cells against cyclosporine toxicity. Autophagy. 2008;4(6): 783-791.

35. Damiano S, Trepiccione F, Ciarcia R, et al. A new recombinant MnSOD prevents the Cyclosporine A-induced renal impairment. Nephrol Dial Transplant. 2013;28(8):2066-2072.

36. Xue XP, Qin XL, Xu C, et al. Effect of Wuzhi tablet (Schisandra sphenanthera extract) on the pharmacokinetics of cyclosporin A in rats. Phytother Res. 2013;27(8):1255-1259.

37. Sun M, Xu XL, Lu QH, Pan QR, Hu X. Schisandrin B: a dual inhibitor of $\mathrm{P}$-glycoprotein and multidrug resistance-associated protein 1. Cancer Lett. 2007;246(1-2):300-307.

38. Wang BL, Yang S, Hu JP, Li Y. Multifaceted interaction of the traditional Chinese medicinal herb Schisandra chinensis with cytochrome P450mediated drug metabolism in rats. J Ethnopharmacol. 2014;155(3): 1473-1482.

39. Lai L, Hao H, Wang Q, et al. Effects of short-term and long-term pretreatment of Schisandra lignans on regulating hepatic and intestinal CYP3A in rats. Drug Metab Dispos. 2009;37(12):2399-2407.

40. Amundsen R, Asberg A, Ohm IK, Christensen H. Cyclosporine A- and tacrolimus-mediated inhibition of CYP3A4 and CYP3A5 in vitro. Drug Metab Dispos. 2012;40(4):655-661.

41. Qin XL, Chen X, Wang Y, et al. In vivo to in vitro effects of six bioactive lignans of Wuzhi tablet (Schisandra Sphenanthera extract) on the CYP3A/P-glycoprotein-mediated absorption and metabolism of tacrolimus. Drug Metab Dispos. 2014;42(1):193-199.

42. Klawitter J, Klawitter J, Schmitz V, et al. Low-salt diet and cyclosporine nephrotoxicity: changes in kidney cell metabolism. J Proteome Res. 2012;11(11):5135-5144.

43. El-Gowelli HM, Helmy MW, Ali RM, El-Mas MM. Celecoxib offsets the negative renal influences of cyclosporine via modulation of the TGF-beta 1/IL-2/COX-2/endothelin ETB receptor cascade. Toxicol Appl Pharmacol. 2014;275(2):88-95.

44. Chyau C-C, Chen C-C, Chen J-C, Yang T-C, Shu K-H, Cheng C-H. Mycelia glycoproteins from Cordyceps sobolifera ameliorate cyclosporine-induced renal tubule dysfunction in rats. JEthnopharmacol. 2014;153(3):650-658.

45. Zhu S, Wang Y, Chen M, et al. Protective effect of schisandrin B against cyclosporine A-induced nephrotoxicity in vitro and in vivo. Am J Chin Med. 2012;40(3):551-566.

46. Damiano S, Ciarcia R, Montagnaro S, et al. Prevention of nephrotoxicity induced by cyclosporine-A: role of antioxidants. J Cell Biochem. 2015;116(3):364-369.

47. Tutanc M, Arica V, Yllmaz N, et al. Effects of erdosteine on cyclosporin-A-induced nephrotoxicity. Hum Exp Toxicol. 2012;31(6) 565-573.

48. Seven I, Gul Baykalir B, Tatli Seven P, Dagoglu G. The ameliorative effects of propolis against cyclosporine A induced hepatotoxicity and nephrotoxicity in rats. Kafkas Univ Vet Fak Derg. 2014;20(5): 641-648.

49. Korolczuk A, Maciejewski M, Czechowska G, Orzel-Pankowska M. Ultrastructural examination of renal tubular epithelial cells and hepatocytes in the course of chronic cyclosporin A treatment-A possible link to oxidative stress. Ultrastruct Pathol. 2013;37(5):332-339.

50. de Arriba G, Calvinod M, Benito S, Parra T. Cyclosporine A-induced apoptosis in renal tubular cells is related to oxidative damage and mitochondrial fission. Toxicol Lett. 2013;218(1):30-38.

51. Oh SW, Lee ES, Kim S, et al. Bilirubin attenuates the renal tubular injury by inhibition of oxidative stress and apoptosis. BMC Nephrol. 2013; $14: 12$.

52. Schumacher A, Zenclussen AC. Effects of heme oxygenase-1 on innate and adaptive immune responses promoting pregnancy success and allograft tolerance. Front Pharmacol. 2015;5:9. 
53. Park SY, Park DJ, Kim YH, Kim YH, Choi YW, Lee SJ. Schisandra chinensis alpha-iso-cubebenol induces heme oxygenase-1 expression through PI3K/Akt and Nrf2 signaling and has anti-inflammatory activity in Porphyromonas gingivalis lipopolysaccharide-stimulated macrophages. Int Immunopharmacol. 2011;11(11):1907-1915.

54. Checker R, Patwardhan RS, Sharma D, et al. Schisandrin B exhibits anti-inflammatory activity through modulation of the redox-sensitive transcription factors Nrf2 and NF-kappa B. Free Radic Biol Med. 2012; 53(7):1421-1430.

55. Ma Q. Role of Nrf2 in oxidative stress and toxicity. In: Insel PA, editor. Annual Review of Pharmacology and Toxicology. Vol 53. Palo Alto: Annual Reviews; 2013:401-426.

56. Ma Q, He XQ. Molecular basis of electrophilic and oxidative defense: promises and perils of Nrf2. Pharmacol Rev. 2012;64(4):1055-1081.

57. Skoko JJ, Wakabayashi N, Noda K, et al. Loss of Nrf2 in mice evokes a congenital intrahepatic shunt that alters hepatic oxygen and protein expression gradients and toxicity. Toxicol Sci. 2014;141(1):112-119.

58. Sagiroglu T, Kanter M, Yagci MA, Sezer A, Erboga M. Protective effect of curcumin on cyclosporin A-induced endothelial dysfunction, antioxidant capacity, and oxidative damage. Toxicol Ind Health. 2014; 30(4):316-327.

59. Azad MAK, Akter J, Rogers KL, Nation RL, Velkov T, Li J. Major pathways of polymyxin-induced apoptosis in rat kidney proximal tubular cells. Antimicrob Agents Chemother. 2015;59(4):2136-2143.

60. Cavalcanti BC, da Costa PM, Carvalho AA, et al. Involvement of intrinsic mitochondrial pathway in neosergeolide-induced apoptosis of human HL-60 leukemia cells: the role of mitochondrial permeability transition pore and DNA damage. Pharm Biol. 2012;50(8):980-993.
61. Song R, Harris LD, Pettaway CA. Downmodulation of Bcl-2 sensitizes metastatic LNCaP-LN3 cells to undergo apoptosis via the intrinsic pathway. Prostate. 2010;70(6):571-583.

62. Rehman H, Krishnasamy Y, Haque K, et al. Green tea polyphenols stimulate mitochondrial biogenesis and improve renal function after chronic cyclosporin a treatment in rats. PLoS One. 2014;8(6):e65029.

63. Guo CZ, Yuan H, He ZP. Melamine causes apoptosis of rat kidney epithelial cell line (NRK-52e cells) via excessive intracellular ROS (reactive oxygen species) and the activation of p38 MAPK pathway. Cell Biol Int. 2012;36(4):383-389.

64. Kim SH, Kim YS, Kang SS, Bae K, Hung TM, Lee SM. Anti-apoptotic and hepatoprotective effects of gomisin A on fulminant hepatic failure induced by D-galactosamine and lipopolysaccharide in mice. J Pharmacol Sci. 2008;106(2):225-233.

65. Hwang IS, Kim JE, Lee YJ, et al. Protective effects of gomisin A isolated from Schisandra chinensis against CCl4-induced hepatic and renal injury. Int J Mol Med. 2013;31(4):888-898.

66. Sureshbabu A, Ryter SW, Choi ME. Oxidative stress and autophagy: crucial modulators of kidney injury. Redox Biol. 2015;4:208-214.

67. Pallet N, Anglicheau D. Autophagy: a protective mechanism against nephrotoxicant-induced renal injury. Kidney Int. 2009; 75(1):118-119.
Drug Design, Development and Therapy

\section{Publish your work in this journal}

Drug Design, Development and Therapy is an international, peerreviewed open-access journal that spans the spectrum of drug design and development through to clinical applications. Clinical outcomes, patient safety, and programs for the development and effective, safe, and sustained use of medicines are a feature of the journal, which

\section{Dovepress}

has also been accepted for indexing on PubMed Central. The manuscript management system is completely online and includes a very quick and fair peer-review system, which is all easy to use. Visit http://www.dovepress.com/testimonials.php to read real quotes from published authors.

Submit your manuscript here: http://www.dovepress.com/drug-design-development-and-therapy-journal 